\title{
Contracting Externalities and Mandatory Menus in the U.S. Corporate Bankruptcy Code
}

\author{
Antonio E. Bernardo \\ Alan Schwartz \\ Ivo Welch
}

December 1, 2014

\begin{abstract}
Our paper offers the first justification for the U.S. bankruptcy code, in which firms are not allowed to commit themselves ex-ante in their lending agreements either to (Chapter 7) liquidation or to (Chapter 11) reorganization in case of distress ex-post. If fire-sale liquidation imposes negative externalities on their peers, then firms can be collectively better off if they are all forced into a no-opt-out choice (a mandatory "menu"). This is the case even though they would individually want to commit themselves to liquidation, and it is collectively better for them than voluntary contract choice or mandatory liquidation. Our paper's innovation is thus to show not when a later choice should be prohibited, but when a later choice should be mandatory. Equivalent analyses could justify when other ex-post choices should remain inalienable (not contractible).
\end{abstract}

JEL Codes: G33 (Bankruptcy, Liquidation). D62 (Externalities). K12 (Contract Law). 
Commercial law usually sets out default procedures for structuring private arrangements but does not require their use. For example, the Delaware Corporate Code permits entrepreneurs to choose among seven default business structures. ${ }^{1}$ Entrepreneurs can contract for the form that best suits their enterprise and even choose alternatives completely different from these defaults. Article 2 of the Uniform Commercial Code, America's leading commercial statute, permits parties to alter every term, except those regulating transactions for procedural fairness. This seems broadly consistent with an economically-minded approach to regulation. Contract theory suggests that when information is symmetric and transactions do not create externalities, the state cannot improve the welfare of the contracting parties by substituting the regulator's view for the parties' view. The commercial laws facilitate this, because courts and legislatures believe that these two conditions-symmetric information and no externalities-commonly obtain.

Bankruptcy law is different.

Although bankruptcy law provides an insolvent debtor with a menu, under which it can liquidate under Chapter 7 or reorganize under Chapter 11, this menu is mandatory. A borrower cannot agree with its creditors in the lending agreement that it will use one or the other of these two procedures if it becomes distressed. Instead, the law always preserves the insolvent borrower's freedom to choose ex-post. ${ }^{2}$ In addition, the U.S. Bankruptcy Code contains a large number of other mandatory rules. For example, a buyer cannot agree in a long-term procurement contract to excuse a solvent seller from further performance if the buyer becomes insolvent during the term. Instead, the distressed buyer can "assume" the contract, and thereby require the seller to perform the rest of it (Che and Schwartz (1999)).

Why should professional borrowers and lenders not be allowed ex-ante to contract for the insolvency procedure that they themselves deem best for them? After all, could the parties not internalize ex-ante any ex-post externalities that attend their debt contracts?

Bankruptcy law therefore remains an apparent anomaly. By the logic of common commercial law, the procedures in the bankruptcy menu should be defaults that firms could

\footnotetext{
${ }^{1}$ The structures are the general (i.e., public) corporation, the close corporation, a limited liability (LLC) company that can be owner-managed or manager-managed, a general partnership, a limited liability partnership (LLP), a limited liability limited partnership (LLLP), and a statutory business trust.

${ }^{2}$ The prohibition on bankruptcy contracting is generally descriptive (see Schwartz (1993, note 10)). Even carve-out and collateralized securities as well as leased assets nowadays provide no more than a partial opportunity for firms to opt out of Chapter 11. Any Federal bankruptcy filing stays asset repossession. The creditors can take collateral only if (a) the debtor has no equity in the asset, and (b) the collateral is not necessary for a successful reorganization.
} 
contract away from, and the Bankruptcy Code could contain fewer mandatory rules. (These rules could serve primarily to enforce lending terms and contracts written earlier.)

Our paper retains the assumptions that parties to lending agreements are sophisticated and that information among contracting parties is symmetric. (Relaxing these assumptions is unlikely to strengthen the case for free contracting.) Yet, we show that plausible circumstances exist in which borrowers as a group are better off with a mandatory bankruptcy menu. Indeed, we show that this follows immediately, though not obviously, from the presence of a familiar externality that theories of bankruptcy codes have neglected: firms that liquidate in financial distress impose an externality on other liquidating firms (Shleifer and Vishny (2011a)). The more firms liquidate, the lower are the prices of liquidated assets for all bankrupt firms. Thus, we show that it is quite possible that a mandatory no-opt-out menu can reduce the externality by just enough to be better than either voluntary contracting choice or an outright prohibition of liquidation.

In our model, individual atomistic firms can decide on their debt levels, given a distress legal code. Our firms exist in a competitive equilibrium, and their individual debt determines the aggregate debt (which itself influences their individual choices). Their own debt levels also determine their individual and collective bankruptcy probabilities. We first show that if the state were to provide only a Chapter-7-like liquidation insolvency procedure, ${ }^{3}$ firms would still lever up considerably and fire sales would be common. We then show that the state can improve the welfare of all firms by allowing firms to have a Chapter-11like reorganization alternative in distress. The ex-post choice of procedure (Chapter 7 or Chapter 11) increases the debt that firms take on ex-ante and thereby increases the frequency of financial distress. However, we show that, net in net, an ex-post choice still ends up reducing the number of firms that will liquidate ex-post (in Chapter 7). A bankruptcy code with an option to reorganize (in Chapter 11) can then be better for firms than a bankruptcy code without it.

If reorganization enhances value, why not let firms choose this option themselves? The answer is that borrowers that are free to contract ex-ante for a bankruptcy procedure may make collectively inefficient choices in a "freedom-of-contract" world. Every firm may become "trapped" in a liquidation-only procedure.

\footnotetext{
${ }^{3}$ Some countries provide only a liquidation procedure. For example, in Sweden insolvent firms are required to be sold promptly after bankruptcy. The average sale is conducted within two months.
} 
To see why, first consider the tradeoffs in a voluntary-contract world. On the one hand, reorganization is costly: the procedure itself is lengthy and litigation centered. ${ }^{4}$ The firm's management will also receive private benefits from continuance and be prone to over-continue. On the other hand, liquidation incurs some direct cost, too, and liquidation values are lower when more other firms also liquidate.

When the expected reorganization costs are low and managers can be reasonably trusted to make good choices, then firms may choose to contract to a managerial-choice procedure (a "menu"). When the expected reorganization costs are high, firms may choose to commit to a liquidation-only procedure, despite low expected fire-sale prices. In any case, each firm takes only its own costs into account ex-ante when choosing its ex-post bankruptcy procedure.

In some parameter ranges, there may not be an equilibrium in which all firms voluntarily commit to a menu. To see why, assume that all firms except firm $i$ have contracted ex-ante to have choice of procedure ex-post. With fewer liquidations and thus higher firesale asset prices in equilibrium, and if reorganization costs are reasonably high, then each firm $i$ may have an incentive to defect (by committing to liquidation in its debt contract). Hence, the conditions that induce firms to prefer liquidation when other firms liquidate also induce firms to prefer liquidation when other firms reorganize. ${ }^{5}$ Under such circumstances, over a wide range of plausible parameters, firms free to choose then liquidate too often from a firm-collective perspective-and it is then that the state can improve firms' welfare by requiring that bankrupt firms must have access to both procedures.

If firms can ex-ante fully internalize the manager's private benefits ex-post (if there are no agency problems), then the bankruptcy code is redundant. This is because firms would always choose the in-distress menu procedure themselves. ${ }^{6}$ This is a knife-edge case in the sense that, while it is true that the forced menu code in the U.S. does not help firms, it also does not harm them. The code merely directs firms to do what they would do all along voluntarily. However, if private managerial benefits and agency conflicts loom just a little larger, then firms individually prefer to switch to a forced-liquidation debt contract, even though this leads to too much liquidation from their collective perspective. It is in these

\footnotetext{
${ }^{4}$ U.S. bankruptcy procedures take between twelve and twenty months. Also, many required decisions are made by the bankruptcy court after notice and a hearing. Thus, litigation costs are high in Chapter 11 .

${ }^{5}$ The intuitive presentation above suggests that the conditions that induce firms to stay with liquidation are similar to the conditions that induce firms to defect from a reorganization procedure. In the model below, we show that these conditions are exactly the same.

${ }^{6}$ There is one agency conflict between managers and firm owners, and another between equity and debt. In the real world, both are likely to be reduced but not fully resolved by contracts. In Section VI.A, we allow owners to "bribe" managers in financial distress to better align their incentives.
} 
cases that the forced-menu U.S. code becomes helpful (and not just harmlessly indifferent). And, finally, if private benefits are extremely high, then it becomes better allowing firms to write forced-liquidation into their debt contracts, after all.

Note that the forced-menu code is not just an elaborate mechanism to overcome the managerial preference to continue too often. In fact, the forced menu makes firms worse off when the managerial continuation bias is too high. Instead, the bankruptcy code is a limited government intervention that reduces the liquidation externality in an intermediate region. Again, it does no harm for low values of private managerial benefits; does good for medium values; and does harm for high values.

Importantly, we cannot claim that the welfare of the contracting parties is necessarily social welfare. Our model is designed to help understand how current bankruptcy rules function. It does not advocate a particular legal code. We cannot state that one system is better than another, because our model ignores the welfare benefits of potential vulture buyers who would be able to purchase liquidating assets at lower scrap prices. Their social benefits-the non-creditor non-firm alternative use of the assets-may be high or low. If the external liquidation benefits are high, then our model is consistent with a view that codes are designed to aid the commercial parties to the lending agreements (the "chamber of commerce") and not society as a whole. If the external liquidation benefits are low, then the social interest of the contracting parties can coincide with that of society as a whole.

Section I sets out our model. Section II analyzes a bankruptcy code that permits either forced reorganization or forced liquidation, but not both. Section III solves the case in which the bankruptcy code contains a menu (Chapter 7 liquidation or Chapter 11 reorganization)as it does in the United States. Section IV lays out the conditions under which the mandatory no-opt-out U.S. bankruptcy code makes firms better off than a code that would allow firms to contract for a procedure themselves. Section $V$ illustrates the model with an extended numerical example. Section VI discusses the context of the model, including the relaxation of our assumptions (including a model in which owners can bribe managers to make better decisions) and the related literature on (legal) remedies of externalities. Section VII outlines an analogous argument in the context of Preferences in the bankruptcy law, and Section VIII concludes. The appendices contain the more technical proofs, and the tables and figures (including a glossary of notation). 


\section{The Model}

Our model is designed to capture some key aspects of corporate bankruptcy. Its ingredients are intentionally minimalist. Firms' debt choices influence both their probabilities of becoming distressed later and their payoffs if distressed. When liquidating, firms impose a "fire-sale" externality on other liquidating firms. ${ }^{7}$ We assume that each firm is atomistic. Firms take as given other firms' debt choices when deciding on their own debt levels, but they cannot coordinate their liquidation choices. They realize that the aggregate behavior of firms is determined by firms like themselves, which they can only anticipate but not influence.

\section{A Model Timing}

Table 1 summarizes the variables. Our model has two dates:

$\begin{array}{cc}\stackrel{\text { Date } 0}{\longrightarrow} \longrightarrow \\ \text { Bankruptcy Code in Place } & \text { Date } 1 \\ \text { Firm values } \widetilde{V}_{i} \sim U[0, \gamma] & \text { Unlevered value } V_{i} \text { revealed } \\ \text { Firms issue debt } D & \text { Distressed if } V_{i}<D . \\ \text { Executed according to code }\end{array}$

At date 0 , the distribution of continuation values for firm $i, \widetilde{V}_{i}$, under zero leverage (when the debtor is not liquidated) is common knowledge. To make the model tractable, we assume that $\widetilde{V}_{i}$ is distributed iid uniform on $[0, \gamma]$. Until Section IV, the bankruptcy resolution system (the "bankruptcy code") at date 1 is exogenous and in place, as explained in detail below. Risk-neutral firms choose how much debt $D$ to take on to maximize their own values. Debt confers a proportional benefit of $\lambda \cdot D$, which for simplicity the firm receives immediately and which is not dissipated by subsequent events. The exogenous parameter $\lambda$ can reflect the ability of debt to allow financially-constrained firms to take on more productive projects, any positive incentive effects from debt, or debt's preferred tax treatment (which may or may not be socially valuable). The firm's only ex-ante choices is

\footnotetext{
${ }^{7}$ As Shleifer and Vishny (2011b, p.30) write, "When a fire sale leads to a sharp reduction in an asset's price, similar assets held by other market participants decline in value as well, which might bring them also to financial distress and forced asset sales. This self-reinforcing process can lead to downward spirals or cascades in asset prices and net worth of market participants. Because of fire sales, risk becomes systemic."
} 
over its leverage $D .{ }^{8}$ As the timing diagram shows, firms choose debt levels before they learn their types, which prevents firms from using debt to signal their types.

At date 1, each manager $i$ learns the unlevered value of the firm's assets $V_{i}$ if the firm continues to operate. A firm whose debt exceeds its value $\left(D>V_{i}\right)$ enters financial distress. ${ }^{9}$ The firm is then treated as required by the applicable bankruptcy code. Below, we will derive equilibria in which firms choose their debt levels $D^{*}$ to maximize their own values and have probabilistically correct ex-ante conjectures about the behavior of other firms.

We analyze only parameter regions in which (a) firms always operate if they are not in distress; (b) the efficiency gains from debt are high enough to prevent firms from liquidating immediately; (c) the probabilities of liquidation, reorganization and no distress are between zero and one; and (d) firms' debt levels are below their expected value. The first restriction is not important in our model because non-distressed firms will be the highest-value firms, who would not want to liquidate when distressed firms do not want to liquidate. The restriction is also consistent with a view that firms cannot commit existing managers to liquidate firms absent distress. Debt may therefore serve the function not only of permitting borrowers to realize the $\lambda$ gain but also of allowing firms to force conditional liquidation (Section B), or at least a decision whether to liquidate or continue in the future (Section III). Finally, we impose the interpretation restrictions, $\gamma>0, \lambda>0, L>0, \kappa>0$, and $\phi>0$. Model solutions that satisfy our parameter restrictions exist for a broad intermediate range of lambda, the exact region of which is spelled out in Appendix B.

\footnotetext{
${ }^{8}$ The firm cannot contract ex-ante to prescribe value-contingent behavior for (or compensation to) managers ex-post. Schwartz (1997) develops a contract that creditors can write with the borrower that presupposes the existence of two mandatory bankruptcy procedures and that induces the managers to overcome their continuation bias and so choose whichever of the two procedures is optimal ex-post. That analysis is complementary to the analysis here.

${ }^{9}$ We assume the distress stage is automatically triggered whenever $V_{i}<D$. Managers cannot hide this value from creditors. If management has more holdup power in distress and some discretion, they could default even if $V_{i}>D$.
} 


\section{Single-Procedure Bankruptcy Codes}

In this section, we derive the behavior of firms if the prevailing bankruptcy code commits distressed firms to reorganize; and then their behavior if the code commits them to liquidate.

\section{A A Bankruptcy Code with Only the Reorganization Procedure}

We first consider a code in which firms are forced to reorganize. Reorganizing firms are worth $V_{i}-\phi \cdot\left(D-V_{i}\right)$, where $\phi \cdot\left(D-V_{i}\right)$ is a dissipative cost, given an exogenous cost parameter $\phi$. It measures both direct and indirect costs, such as costs from debt overhang and risk-shifting. There are no externalities, because there are no asset sales. Figure 1 illustrates the sequence of actions. The only firm choice is $D$. Firms that choose $D$ immediately receive the efficiency benefit of debt $\lambda \cdot D$. However, a higher $D$ increases the probability of distress and reduces the expected payoff in distress. Because value is uniformly distributed from 0 to $\gamma$, the probability of being in distress is $D / \gamma$ for $0<D<\gamma$. Figure 2 illustrates the debt-contingent value of firms. For realizations of $V$ far below $D$, the owner-creditors walk away. For medium realizations, the creditors reorganize the firm. For high realizations, the firm does not experience distress.

There are no interaction among firms. Therefore, each firm chooses debt to maximize

$$
\max _{D} \int_{0}^{D} \max [0, V-\phi \cdot(D-V)] \cdot\left(\frac{1}{\gamma}\right) d V+\int_{D}^{\gamma} V \cdot\left(\frac{1}{\gamma}\right) d V+\lambda \cdot D .
$$

It is straightforward to derive the following result:

Lemma 1 When only reorganization is permitted in financial distress, the firm's optimal debt choice is

$$
D^{R O}=\gamma \cdot \lambda \cdot(1+\phi) / \phi
$$

and the date 0 firm value is

$$
V^{R O}=\gamma \cdot\left[1+(1+\phi) \cdot \lambda^{2} / \phi\right] / 2
$$

where the superscript $R O$ denotes that these are the reorganization-only optimal values.

In equilibrium, both debt and firm value increase in scale $\gamma$ and debt benefits $\lambda$ and decrease in the friction $\phi$. 


\section{B A Bankruptcy Code with Only the Liquidation Procedure}

We now consider the code in which distressed firms must liquidate their assets and liquidations can induce fire-sale-like externalities. The liquidation price is $L-\kappa \cdot \alpha^{*}$, which depends on the fraction $\alpha^{*}$ of firms that liquidate contemporaneously and two exogenous parameters, $L$ and $\kappa$. The parameter $\kappa$ measures the inverse of the market depth. It is economically interpretable as measuring asset-specificity: when $\kappa$ is higher, liquidation asset prices are lower. The parameter $L$ is a baseline value if no (other) firm liquidates or if a firm liquidates assets when not distressed. $L$ is a free parameter, but it will be (modestly) constrained below. Importantly, the asset values are identical in liquidation while the continuation values $V_{i}$ differ across firms. ${ }^{10}$ Thus, the liquidation value can be interpreted as the value of assets if put to another use. Figure 3 again illustrates the sequence of actions, and Figure 4 again illustrates the debt-contingent value to firms.

Although the firms' debt choices aggregate to determine the fraction of firms that liquidate in equilibrium $\left(\alpha^{*}\right), \alpha^{*}$ is exogenous from the firm's optimization perspective. Firms are identical ex-ante so symmetry among them determines the equilibrium $\alpha$. Again, because value is uniformly distributed from 0 to $\gamma$, the probability of being in distress is $D / \gamma=\alpha$ for $0<D<\gamma$. Firms in distress receive $L-\kappa \cdot \alpha$, where $\alpha$ is the firm-exogenous fraction of firms that the firm (correctly) conjectures will be liquidating. Firms not in distress receive $V_{i}$.

The optimization and allocation can also be diagrammed as

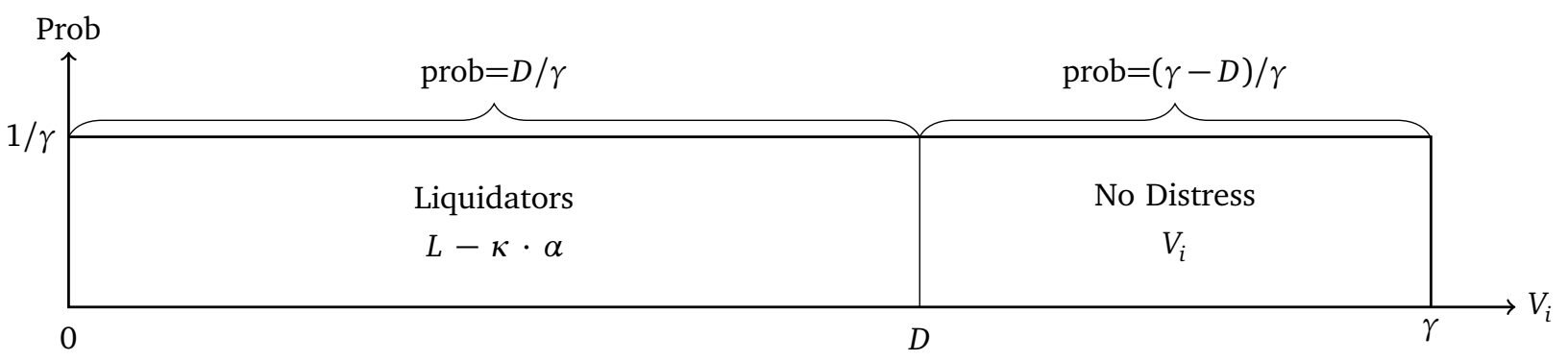

Eqbm: $\alpha \cdot \gamma \equiv D$

Again, in addition, firms that choose $D$ immediately receive the efficiency benefit of debt $\lambda \cdot D$. We are interested in the following equilibrium:

\footnotetext{
${ }^{10}$ In the model, there is no inference that earlier liquidators have lower asset values. Rather, $L$ is independent of other firms' liquidation choices. The externality is fully in the asset specificity variable $\kappa$. The model could be extended to allow for (modest) associations of value in liquidations, too. This would be similar to the generalization where liquidations have an externality on remaining firms, discussed below.
} 
Equilibrium Definition 1 (LO) A symmetric equilibrium is a choice of debt, $D^{*}$, with a consequent proportion of firms forced to liquidate, $\alpha^{*}$, such that:

1. Given $\alpha, D^{*}(\alpha)$ solves:

$$
\max _{D} \int_{0}^{D}(L-\kappa \cdot \alpha) \cdot\left(\frac{1}{\gamma}\right) d V+\int_{D}^{\gamma} V \cdot\left(\frac{1}{\gamma}\right) d V+\lambda \cdot D .
$$

2. $\alpha^{*}=\operatorname{Pr}\left[V_{i} \leq D^{*}\left(\alpha^{*}\right)\right]$.

We can now solve for this equilibrium. The FOC of (3) can be rearranged to

$$
D(\alpha)=L-\kappa \cdot \alpha+\gamma \cdot \lambda,
$$

which gives the optimal debt level, as a function of the anticipated fraction of firms liquidating. A firm wants to take on less debt when the specificity of its assets is high and it believes that many firms will liquidate as well. On the other hand, debt is attractive to the firm when it is productive and when the firm's project may be highly profitable (i.e., $\lambda$ and $\gamma$ are high).

Debt, however, also imposes an externality because more firms liquidate when aggregate debt is higher,

$$
\alpha(D)=D / \gamma .
$$

Substituting this anticipated equilibrium fraction into the above expression gives the symmetric equilibrium for the optimal debt choice and the consequent proportion of liquidating firms.

Lemma 2 The symmetric equilibrium when only liquidation is permitted in distress is

$$
D^{\llcorner 0}=\gamma \cdot\left(\frac{L+\gamma \cdot \lambda}{\gamma+\kappa}\right), \alpha^{\llcorner O}=\frac{D^{\llcorner 0}}{\gamma},
$$

and the date-0 equilibrium firm value is

$$
V^{\llcorner 0}=\frac{\gamma}{2} \cdot\left[1+\left(\frac{L+\gamma \cdot \lambda}{\gamma+\kappa}\right)^{2}\right]
$$

where the superscript $L O$ denotes that these are the liquidation-only optimal values. 
In equilibrium, firms incur more debt when their expected continuation values are higher; liquidation prices $(L)$ are higher; asset-specificity $(\kappa)$ is lower; and debt $(\lambda)$ is more productive. Firm value is increasing in expected continuation values $(\gamma)$, the liquidation value $(L)$, and the benefit of debt $(\lambda)$, and is decreasing in asset specificity $(\kappa)$.

\section{A Bankruptcy Code with A Menu Procedure}

We now consider a bankruptcy code in which distressed firms can choose themselves ex post whether to liquidate their assets or whether to reorganize. This characterizes the U.S. code, except we consider it voluntary from the firm perspective in this section. Figure 5 illustrates the sequence of actions in this scenario with choice. The managers can liquidate under Chapter 7 , in which case the creditors receive $L-\kappa \cdot \alpha$, or the managers can reorganize under Chapter 11, in which case the creditors receive $\max \left\{0, V_{i}-\phi \cdot\left(D-V_{i}\right)\right\}$.

In addition, we assume that the managers' incentives to continue in default differ from those of the creditors. In our model, this conflict of interest is described by a parameter $\beta$ : when $\beta$ is zero, the manager acts in the interest of the firm; when $\beta$ is positive, she wants to continue too often; and when $\beta$ is negative, she wants to liquidate too often. It is widely accepted that $\beta$ is positive. There are many reasons, among them the fact that the incumbent equity (as debtors-in-possession) have an option on the value of a continuing firm, and they would often receive zero in an immediate liquidation (e.g., Decamps and Faure (2002)). We assume that this conflict of interest is not fully internalized by the firm. ${ }^{11}$

There is a critical equilibrium value $\bar{V}$ below which all managers with values $i$ prefer to liquidate, and above which all managers prefer to continue. Borrowers find reorganization to be relatively more desirable when $V_{i}$ is larger because the liquidation value is independent of $V$. Therefore, in equilibrium, if the manager of firm $i$ prefers to continue/reorganize rather than to liquidate, so will all managers whose continuation values are higher than those of firm i.

Figure 6 illustrates the debt-contingent payoffs. A reorganizing firm $i$ whose value $V_{i}$ is less than $D$ incurs financial distress costs that increase linearly in $D-V_{i}$. The firm also can

\footnotetext{
${ }^{11}$ If the continuation bias were fully internalized by the firm, then no harm is done by a forced menu. We can show in a modified model in which the firms fully internalize $\beta$ upfront, they always voluntarily choose a debt contract with a menu over a debt contract with forced liquidation.
} 
realize a liquidation value that is independent of $V$, and that is a function of the fraction of firms that liquidate in equilibrium, $\alpha$. Managers choose to continue if and only if

$$
V_{i}-\phi \cdot\left(D-V_{i}\right)+\beta \geq L-\kappa \cdot \alpha \quad \Leftrightarrow \quad V_{i} \geq \frac{L-\kappa \cdot \alpha+\phi \cdot D-\beta}{1+\phi} \equiv \bar{V} .
$$

Expression (8) shows that the managers' choice whether to liquidate or to reorganize depends not only on the liquidation value $(L-\kappa \cdot \alpha)$ relative to the reorganization value $\left(V_{i}-\phi \cdot\left(D-V_{i}\right)\right)$, but also on the continuation bias $\beta$. Again, firms have control over their own debt levels, which influence their ultimate collective choices whether to liquidate or continue, but they cannot coordinate on an equilibrium $\alpha$.

Thus, equilibrium now is a pair $(\bar{V}, D)$, such that firms choose debt $D$ to maximize their values ex-ante, managers maximize their own objective functions when deciding whether to liquidate or continue if financial distress occurs, and firms anticipate the behavior of their managers correctly. In equilibrium, all firms with values between 0 and $\bar{V}$ liquidate; all firms with values between $\bar{V}$ and $D$ reorganize, and all firms with values above $D$ are not distressed. The probabilities of liquidation, reorganization, and no distress for a firm with debt $D$ are $\bar{V} / \gamma,(D-\bar{V}) / \gamma$, and $(\gamma-D) / \gamma$, respectively.

Using the same diagram as before, the probabilities and payoffs are now

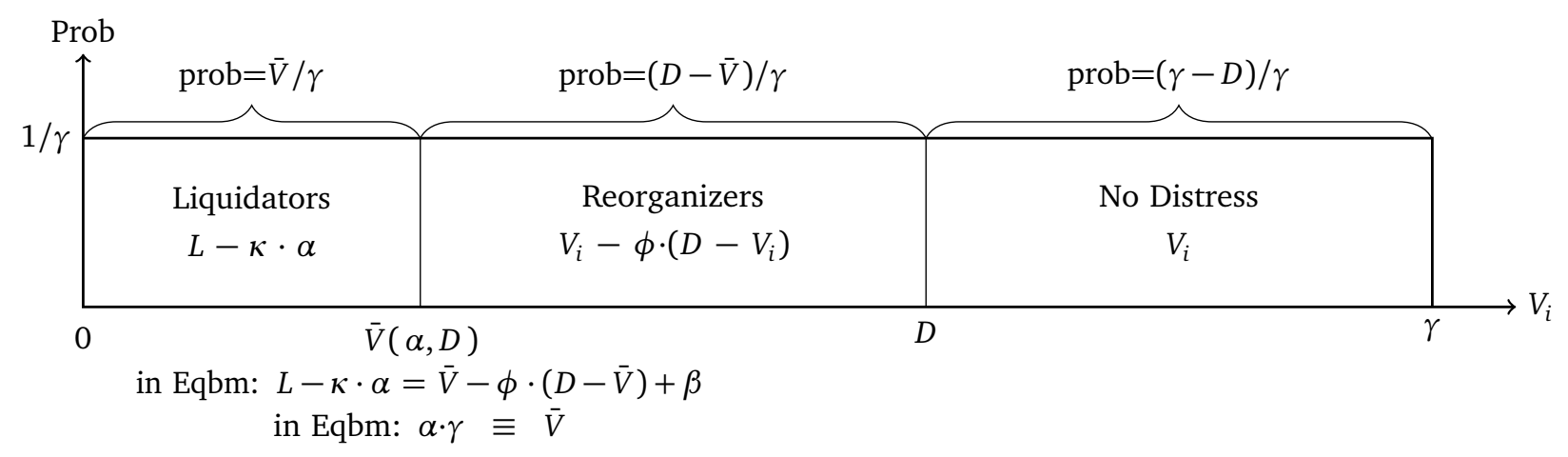

We can define the equilibrium more formally as

Equilibrium Definition 2 (LR) A symmetric equilibrium is a choice of debt, $D^{*}$, and a proportion of firms that liquidate, $\alpha^{*}$, such that:

1. In the event of distress, the manager chooses to liquidate if and only if $V_{i} \leq \bar{V}(\alpha, D)$. 
2. Given $\alpha, D^{*}(\alpha)$ solves:

$$
\begin{gathered}
\max _{D} \int_{0}^{\bar{V}}(L-\kappa \cdot \alpha) \cdot\left(\frac{1}{\gamma}\right) d V+\int_{\bar{V}}^{D}[V-\phi \cdot(D-V)] \cdot\left(\frac{1}{\gamma}\right) d V \\
+\int_{D}^{\gamma} V \cdot\left(\frac{1}{\gamma}\right) d V+\lambda \cdot D .
\end{gathered}
$$

3. $\alpha^{*}=\operatorname{Pr}\left[V_{i} \leq \bar{V}\left(\alpha^{*}, D^{*}\left(\alpha^{*}\right)\right)\right]$.

Substituting $\bar{V}$ into (9), integrating, and setting the derivative to zero gives the optimal debt choice in terms of $\alpha$,

$$
D(\alpha)=L-\alpha \cdot \kappa+\gamma \cdot \lambda \cdot(1+1 / \phi) .
$$

As in (4), firms want to take on less debt if they believe that more firms will liquidate in equilibrium.

The second equilibrium condition is again that the anticipated fraction of liquidators is correct. By definition, $\bar{V}=\alpha \cdot \gamma$, and thus the equivalent of (5) is

$$
\alpha(D)=\frac{L+\phi \cdot D-\beta}{(1+\phi) \cdot \gamma+\kappa} .
$$

When (aggregate) debt is higher, more firms will liquidate. Note, however, that the fraction of firms that liquidate is falling in $\beta$, the managers' continuation bias.

These two equations and two unknowns define the symmetric equilibrium solution.

Lemma 3 The equilibrium when managers can choose between liquidation and reorganization in distress is

$$
\begin{aligned}
& D^{L R}=\underbrace{\gamma \cdot\left(\frac{L+\gamma \cdot \lambda}{\gamma+\kappa}\right)}_{D^{L O}}+\frac{\beta \cdot \kappa}{(\gamma+\kappa) \cdot(1+\phi)}+\frac{\gamma \cdot \lambda}{\phi}, \\
& \alpha^{L R}=\underbrace{\left(\frac{L+\gamma \cdot \lambda}{\gamma+\kappa}\right)}_{\alpha^{L O}}-\frac{\beta}{(\gamma+\kappa) \cdot(1+\phi)}, \\
& \bar{V}^{L R}=\alpha^{L R} \cdot \gamma .
\end{aligned}
$$


Substituting $\alpha^{L R}, \bar{V}^{L R}$, and $D^{L R}$ into the firm's objective function yields the equilibrium value of the firm $V^{L R}$ when all firms function under the menu code: ${ }^{12}$

$$
\begin{gathered}
{\left[2 \cdot \phi \cdot \gamma \cdot(\gamma+\kappa)^{2} \cdot(1+\phi)^{2}\right]^{-1} \times} \\
\left(-\beta^{2} \cdot \phi \cdot\left[\gamma \cdot(\gamma+2 \cdot \kappa)+(\gamma+\kappa)^{2} \cdot \phi\right]+2 \cdot \beta \cdot \gamma \cdot \kappa \cdot \phi \cdot(1+\phi) \cdot(L+\gamma \cdot \lambda)+\right. \\
\left.\gamma^{2} \cdot(1+\phi)^{2} \cdot\left\{\left[(\gamma+\kappa)^{2}+L^{2}\right] \cdot \phi+2 \cdot \gamma \cdot L \cdot \phi \cdot \lambda+\left[(\gamma+\kappa)^{2}+\gamma^{2} \cdot \phi\right] \cdot \lambda^{2}\right\}\right),
\end{gathered}
$$

where the superscript $L R$ denotes that these are the optimal values when firms in financial distress have a choice of liquidation or reorganization.

Inspection of (10) shows that fewer firms liquidate in the with-reorganization scenario than in the forced-liquidation scenario. Because fewer of their peers liquidate, each firm becomes individually more aggressive in its debt choice. However, collectively, firms do not become aggressive enough to increase the in-equilibrium frequency of liquidation. The wedge between liquidating and distressed firms is taken up by reorganizing firms, whose distress does not affect the equilibrium liquidation prices. Yet, even in this voluntary menu procedure, firms still liquidate too often from their collective perspective. ${ }^{13}$

The optimal debt level $\left(D^{L R}\right)$ increases in the debt benefit $(\lambda)$ and the liquidation value $(L)$; and decreases in the dissipative cost $(\phi)$ and the asset specificity $(\kappa)$. The proportion of all firms liquidating in equilibrium $\left(\alpha^{L R}\right)$ increases in the liquidation value $(L)$, the dissipative cost $(\phi)$, and the upper bound on the distribution of continuation values $(\gamma)$. Furthermore, with private benefits $(\beta)$, there are fewer liquidations, because managers continue too often.

Finally, note that $\partial\left(V^{L R}-V^{L O}\right) / \partial \beta<0$. When the managerial conflict of interest $(\beta)$ is small, firms tend to prefer to contract to managerial choice rather than to contract to mandatory liquidation. When the conflict of interest is large, firms do not want their managers to have discretion.

\footnotetext{
${ }^{12} D^{L R}(\lambda=0) \neq 0$ and $V^{L R}(\lambda=0) \neq \bar{V}^{L R}(\lambda=0)$, because the expressions for optimal debt and ex-ante levered value are only true for the parameter region in which $\lambda$ is sufficiently large.

${ }^{13}$ To the extent that governments can impose further costs on liquidation, such "Pigouvian liquidation taxes" could be imposed not only under the mandatory menu but also under free contracting. From our perspective, it is important that they would not completely remove the tendency of firms to liquidate too much. More generally, good Pigouvian liquidation costs on Federal Chapter 7 liquidation are not only difficult to calculate and collect, but also circumventable by firms. Firms could liquidate privately or through state law procedures (Morrison (2009)).
} 


\section{The Meta-Problem: Voluntary Contracting or Mandatory Menu?}

We are now prepared to analyze the problem of interest: Are firms better off if they are free to choose their own bankruptcy codes, or are they better off if they are all required to live in a menu procedure that commits them to choice later-on? We need to consider how firms would behave if they could first choose a bankruptcy code and then a debt level; and then, if they have chosen the menu code, make the additional choice of whether to reorganize or liquidate if they encounter distress. This problem entails considering how the procedural choices of other firms would affect all the choices of each firm.

If the value to a firm's choices of a bankruptcy code were independent of the bankruptcy code of their peers, each firm could individually choose the bankruptcy codes that is best for itself, simply by comparing $V^{R O}, V^{L O}$, and $V^{L R}$. However, each firm's choice over its preferred bankruptcy code affects not only its own ex-ante leverage, but also both the ex-ante bankruptcy code choices and ex-ante leverages of other firms. This alters the in-equilibrium fraction of firms that liquidate, which in turn influences each firm's code and debt decisions.

The externality among firms (stemming from the liquidation fire-sale price) is the reason why a government intervention has the potential to increase expected firm values over the free-market solution. However, note that the externality occurs when the government cannot prohibit or curtail liquidation in the menu code. That is, firms can still liquidate whenever they want, even in the $L R$ code. The question for the state is whether it should prevent the borrower from opting out of the $L R$ menu code (i.e., choosing Chapter 7 or Chapter 11) in the lending agreement: that is, whether the state should preserve the firm's ex-post procedural menu choice or not.

Our model's governmental intervention is quite limited. We do not endow the government with more information than contracting parties, we do not allow it to impose firm-specific or industry-specific remedies, and we do not assume it can enforce mandatorymenu contracts better than voluntary-menu contracts (e.g., due to fixed setup costs for a system with choice of bankruptcy resolution). We only allow it to force a universal menu on parties that could contract to the very same menu by themselves. This obviously limits the scope of where the forced menu can outperform the voluntary menu.

This is not model specific. Any bankruptcy code must judge "only" whether firms would be better or worse off if they and their creditors were forced collectively into menus that 
they would not voluntarily choose themselves. The forced-menu code does no harm or good when firms would choose the very same menu contract voluntarily. That is, any scenarios in which creditors and firms would choose to commit to the same menu by themselves simply cancel out. The code must balance situations in which the forced menu choice improves the social externality (less liquidation) against situations in which the code harms firms by not allowing them to commit to a liquidation procedure that would better mitigate the managerial conflict of interest.

\section{A The Meta Problem}

The problem becomes conceptually easier to understand if we first describe the conditions when a government should intervene to enforce a menu when firms play only pure-strategy equilibria. (We will show later that there are no mixed-strategy equilibria.) There are then three key conditions:

1. The "Chamber of Commerce" Condition: Firms are collectively better off when all firms are in the menu bankruptcy code $L R$ than when all firms are in an alternative code, either a liquidation-only $L O$ or a reorganization-only code $R O$.

2. The "Inferior-Code Stability" Condition: If all (other) firms have chosen a non-menu code, then an individual firm would not want to deviate into the menu code $L R$. Such a non-menu bankruptcy code can trap firms.

These two conditions state that a stable equilibrium is inferior to what the government could enforce. The condition do not yet preclude that the menu bankruptcy code is an equilibrium, too. If an $L R$ bankruptcy code is also an equilibrium, then the government would only have to push firms into this better $L R$ code once, and the equilibrium could then maintain itself. If it is not an equilibrium, then the government would have to remain vigilant.

3. The "Better-Menu-Code Instability" Condition: If all other firms have chosen the menu code $L R$, an individual firm would want to deviate into a non-menu bankruptcy code. The menu bankruptcy code cannot hold firms.

The intuition is that, if its peers have chosen a menu, then each individual firm would want to "free-ride" on the higher liquidation value and commit to liquidate instead. Indeed, it is 
plausible that a recent institutional development in which firms are placing some of their tangible assets into separate corporate entities to make them more "bankruptcy remote" is benefited by the fact that their peers' assets are not (yet) in such entities.

We will show that there are robust parameter regions in which the only equilibrium is a pure forced-liquidation bankruptcy code (LO), in which firms are collectively worse off than they would be if the government enforced the menu bankruptcy code $(L R)$.

We can immediately simplify our problem by showing that choosing $R O$ is never optimal.

Lemma 4 If $\beta \geq 0$, then the reorganization-only $(R O)$ is dominated by the menu (LR) for all beliefs $\alpha$.

Proof: Suppose $\bar{V}\left(D^{R O}\right) \leq D^{R O}$. Then

$$
\begin{array}{rlrl}
V^{L R}(\alpha) & = & \max _{D} & \int_{0}^{\bar{V}}(L-\kappa \cdot \alpha) \cdot\left(\frac{1}{\gamma}\right) \cdot d V+\int_{\bar{V}}^{D}[V-\phi(D-V)] \cdot\left(\frac{1}{\gamma}\right) \cdot d V+\int_{D}^{\gamma} V \cdot\left(\frac{1}{\gamma}\right) \cdot d V+\lambda \cdot D \\
& \geq & \int_{0}^{\bar{V}\left(D^{R O}\right)}(L-\kappa \cdot \alpha) \cdot\left(\frac{1}{\gamma}\right) \cdot d V+\int_{\bar{V}\left(D^{R O}\right)}^{D^{R O}}\left[V-\phi\left(D^{R O}-V\right)\right] \cdot\left(\frac{1}{\gamma}\right) \cdot d V+\int_{D^{R O}}^{\gamma} V \cdot\left(\frac{1}{\gamma}\right) \cdot d V+\lambda \cdot D^{R O} \\
& \geq & \int_{0}^{D^{R O}} \max \left\{0, V-\phi\left(D^{R O}-V\right)\right\} \cdot\left(\frac{1}{\gamma}\right) \cdot d V+\int_{D^{R O}}^{\gamma} V \cdot\left(\frac{1}{\gamma}\right) \cdot d V+\lambda \cdot D^{R O} \\
& = & V^{R O},
\end{array}
$$

where the first inequality follows from the fact that $V^{L R}(\alpha)$ is the maximized value over all feasible choices of debt, $D$, and the second inequality follows from the fact that $L-\kappa \cdot \alpha \geq V-\phi \cdot(D-V)+\beta \geq V-\phi \cdot(D-V)$ for all $V \leq \bar{V}$. A similar argument can be used to show the result if $\bar{V}\left(D^{R O}\right)>D^{R O}$.

Thus, we need to consider only the $L O$ and $L R$ codes. Let $f_{L R}$ be the in-equilibrium fraction of firms that at date 0 select the menu code $L R$ as their date 1 distress procedure. The payoff for a firm is a function of its own choice of code $(C \in\{L O, L R\})$ and the aggregate $f_{L R}$, in addition to the aggregate $\alpha$ fraction of firms liquidating and its own debt choice $D$. For notation, we let $V^{C}\left(f_{L R}\right)$ represent the value of the firm if it has chosen code $C$ and fraction $f_{L R}$ of all firms have chosen code $L R$. We can now write the chamber-of-commerce condition 1 as

$$
V^{L R}\left(f_{L R}=1\right)>V^{L O}\left(f_{L R}=0\right) .
$$

Firms are collectively better off if all firms have chosen to commit to the $L R$ code than if they had all chosen to commit to the $L O$ code. 
We can write the inferior-code equilibrium stability condition 2 as

$$
V^{L O}\left(f_{L R}=0\right)>V^{L R}\left(f_{L R}=0\right)
$$

If all other firms choose the inferior code $\left(f_{L R}=0\right)$, a firm would reduce its value if chose the menu code.

Finally, we can write the better-menu-code instability condition 3 as

$$
V^{L O}\left(f_{L R}=1\right)>V^{L R}\left(f_{L R}=1\right)
$$

Firms would deviate from an equilibrium in which all other firms have chosen to commit to the menu code. Consequently, the government must remain vigilant.

\section{B The Meta Solution}

Our model is about mutual externalities, not about individual firms. In the absence of externalities, the conditions under which a bankruptcy menu code dominates a liquidationonly code (condition 1 ) are also conditions under which all firms could rationally choose the bankruptcy menu code by themselves (violating conditions 2 and 3). More formally,

Lemma 5 If $\kappa=0$ (no liquidation externality), then conditions 1-3 cannot be simultaneously satisfied.

Proof: Our three conditions require (i) $V^{L R}\left(f_{L R}=1\right)>V^{L O}\left(f_{L R}=0\right)$; (ii) $V^{L O}\left(f_{L R}=0\right)>V^{L R}\left(f_{L R}=0\right)$; and (iii) $V^{L O}\left(f_{L R}=1\right)>V^{L R}\left(f_{L R}=1\right)$. If $\kappa=0$ there are no liquidation externalities so $V^{L R}$ and $V^{L O}$ are independent of $f_{L R}$, the proportion of firms choosing $L R$. Hence, our three conditions become (i) $V^{L R}>V^{L O}$, (ii) $V^{L O}>V^{L R}$, and (iii) $V^{L O}>V^{L R}$. These are incompatible.

There is no need for the government to mandate a code. The contracting parties can be left to choose their own optimal procedures. Similarly,

Lemma 6 If $\beta=0$ (no conflict of interest), then conditions 1-3 cannot be simultaneously satisfied.

The proof is straightforward. If firms never have an interest in forcing managers' hands in distress, then each and every firm will commit itself voluntarily to the menu code. In this 
case, there is no need for the government to mandate it. There would also be no harm in it, of course. And

Lemma 7 If $\beta \rightarrow \infty$ (extreme conflict of interest), then conditions 1-3 cannot be simultaneously satisfied.

Again, the proof is straightforward (see equation 10 below). Firms are always better off committing conflicted managers to liquidation.

We can now procede to the model solution. First, we describe the region of the parameter space in which firms are collectively better off if they are all forced into the $L R$ code.

Proposition 1 The condition that all firms are better off collectively in a bankruptcy menu code with no-opt-out compared to codes in which all firms liquidate, $V^{L R}\left(f_{L R}=1\right)>V^{L O}\left(f_{L R}=0\right)$, holds if and only if

$$
\begin{array}{r}
\gamma^{2} \cdot(\gamma+\kappa)^{2} \cdot(1+\phi)^{2} \cdot \lambda^{2}+2 \cdot \beta \cdot \gamma \cdot \kappa \cdot \phi \cdot(1+\phi) \cdot(L+\gamma \cdot \lambda) \\
-\beta^{2} \cdot \phi \cdot\left[\kappa^{2} \cdot \phi+\gamma^{2} \cdot(1+\phi)+2 \cdot \gamma \cdot \kappa \cdot(1+\phi)\right]>0 .
\end{array}
$$

As already shown, the condition that firms are collectively better off in the menu code $L R$ than in the reorganization code $R O$ is always satisfied. The only binding condition is that firms are collectively better off in the $L R$ menu code than in the forced-liquidation code $L O$. This condition holds when the benefits of debt $\lambda$ are higher than some critical value. Intuitively, firms can take on more debt when the Chapter 11 procedure exists than when the Chapter 7 procedure is forced. When the debt benefits are large enough, firms are better off in a collective menu code than in a collective liquidation-only code, even though in the former, managers choose Chapter 11 reorganization too often.

Next, we describe the region where firms cannot end up in an equilibrium where they all offer a menu by themselves without any government intervention. We can show that for a wide parameter region, if no other firm has chosen an alternative $\left(f_{L R}=1\right)$, i.e., if all firms have chosen the menu $L R$, then an individual firm could increase its value by choosing liquidation $L O$. In addition, in any mixed equilibrium, it would have to be the case that $V^{L O}(f)=V^{L R}(f)$ for some interior $f$, so that one marginal firm is indifferent between committing to the forced-liquidation code and the menu code. It turns out that such a 
mixed equilibrium does not exist (except in a knife-edge case). Interestingly, the same condition that assures that the liquidation-only equilibrium $L O$ traps firms assures that the menu code $L R$ cannot hold voluntary participant firms:

\section{Proposition 2 If}

$$
\left(\frac{\beta}{\gamma \cdot \lambda}\right)^{2}>\left(\frac{1+\phi}{\phi}\right)
$$

then (1) there is a unique equilibrium in which all firms choose at date 0 to force liquidation in distress at date 1, i.e., $V^{L O}\left(f_{L R}=0\right)>V^{L R}\left(f_{L R}=0\right)$; and (2) firms would want to defect from a menu code if their peers had chosen a menu code, i.e., $V^{L O}\left(f_{L R}=1\right)>V^{L R}\left(f_{L R}=1\right)$.

The proof is in Appendix A. It also shows that when (11) fails, then there is a unique equilibrium in which all firms choose at date 0 to have the menu bankruptcy code. The liquidation-only LO bankruptcy code is the equilibrium when reorganization costs are high and when private benefits are high.

In the proof, we show that the endogenous debt response to changing liquidation values results in a difference $V^{L O}\left(f_{L R}\right)-V^{L R}\left(f_{L R}\right)$ that is constant for all $f_{L R}{ }^{14}$ In particular, this implies that the two stability conditions are identical: $V^{L O}(1)>V^{L R}(1) \Leftrightarrow V^{L O}(0)>$ $V^{L R}(0)$. In words, firms that would do better choosing liquidation over menu when all other firms choose liquidation $\left(f_{L R}=0\right)$ also would do better choosing liquidation when all other firms choose menu $\left(f_{L R}=1\right)$. For the same reason (that the difference in firm values is constant across procedures), there is no possibility that $V^{L O}\left(f_{L R}\right)=V^{L R}\left(f_{L R}\right)$ for some interior $f_{L R}$ but not for others, except where exogenous parameters happen to be such that all $f_{L R}$ leave firms equally well off with either choice. Except for this knife-edge case, no mixed equilibrium exists.

The intuition for this result is that firm value is increasing in $f_{L R}$ because when more firms commit ex-ante to liquidate rather than menu-choose in case of financial distress, it is also the case that more firms will end up liquidating ex-post. But even if all other firms have committed to forced liquidation $\left(f_{L R}=0\right)$, and forced-liquidation thus is a low-value outcome, an individual firm cannot benefit by defecting to the reorganization procedure. When $\beta$ (the continuation bias of managers) and $\phi$ (the loss in reorganization) are large, the liquidationonly procedure is more attractive to firms. When these parameter values are high, however, the menu procedure is unattractive to firms. The relative value of liquidating $V^{\llcorner O}$ over

\footnotetext{
${ }^{14}$ The constant distance happens to be an artifact of the uniform distribution, but this property is merely convenient and not important for our main argument.
} 
menu $V^{L R}$ depends only on the tradeoff between reorganization cost $(\phi)$ and flexibility cost (allowing conflicted management to continue excessively, $\beta$, normalized by the productivity of debt). ${ }^{15}$

As noted in footnote 2, although the bankruptcy menu choice between Chapter 7 and Chapter 11 is the common procedure of the overall U.S. bankruptcy code, firms can sometimes make reorganization more difficult for themselves. Individual firms would prefer to opt out into a committed-liquidation procedure bankruptcy code in order to free-ride on the lower in-equilibrium liquidation frequency that the U.S. Code affords. Leasing or debt provisions that make reorganization more cumbersome may, at times, also accomplish this.

\section{Sample Solution}

We now illustrate some sample solutions that satisfy our conditions (10) and (11). Start with base values of

\begin{tabular}{cccccc}
$\gamma$ & $L$ & $\lambda$ & $\kappa$ & $\phi$ & $\beta$ \\
\hline 1 & 0.5 & 0.1 & 0.2 & 2 & 0.2
\end{tabular}

These parameter choices satisfy the interpretation requirements and parameter restrictions in Appendix B that assure mathematically-valid and sensible domains on the equilibrium quantities. The chamber-of-commerce condition (eq 10) states that lambda has to exceed 0.0723 , which it does. The equilibrium stability conditions (eq 11) hold because $0.04=$ $0.2^{2}=\beta^{2}$ is greater than $(1+\phi) / \phi \cdot \gamma^{2} \cdot \lambda^{2}=3 / 2 \cdot 1 \cdot 0.1^{2}=0.015$. Thus, these parameters represent a case in which firms are better off if the government does not allow firms to contract out of the menu.

This becomes clearer if we consider the different bankruptcy codes separately. First, in the $R O$ code, where all firms are required to reorganize (but can abandon projects if their post-reorganization value would be negative), their optimal debt is $\gamma \cdot \lambda \cdot(1+\phi) / \phi=0.15$ (eq 1 ) and their ex-ante value is $\gamma \cdot\left(1+(1+\phi) \cdot \lambda^{2} / \phi\right) / 2=1 / 2 \cdot\left(1+0.1^{2} / 2\right)=0.5075$ (eq 2). Second, in the $L O$ code where all firms are required to liquidate, their optimal debt is 0.5 (eq 6) and their ex-ante value is 0.625 (eq 7). Third, in the $L R$ code where all firms are required to have an ex-post menu choice, their optimal debt is $101 / 180$. The equilibrium

\footnotetext{
${ }^{15}$ The liquidation cost parameters ( $L$ and $\kappa$ ) do not influence the stability region because firms use their leverage choices collectively so as to cancel their influence. The productivity of debt, $\lambda$, enters the stability conditions because firms take on more debt in a menu code than they do in a forced-liquidation code.
} 
fraction of firms liquidating is $\alpha^{*}=80 / 180$. With $\gamma=1$, this also is the critical-value level $\bar{V}$ below which firms liquidate rather than reorganize. (Thus, all firms with values below $80 / 180$ liquidate, all firms between $80 / 180$ and 101/180 reorganize, and all firms above $101 / 180$ are not distressed.) The ex-ante value of the firm is $0.1827+0.0450+0.3426 \approx$ 0.62645. Of the three possible bankruptcy codes, the best is the one in which firms are required to have the menu choice $L R$.

Now consider what an individual firm free to choose would want to do if all other firms were committed to having a menu $(L R)$. If it could commit itself to liquidation, the best way to do so would be to take on debt of $0.5 \overline{1}$ (less than the $0.56 \overline{1}$ that its peers are choosing). It would then be worth 0.6306 , more than the 0.6265 that other firms are worth. Thus, an individual firm would want to defect. The menu code $L R$ is not an equilibrium that can hold firms that are free to commit themselves to forced-liquidation $L O$ instead.

Now consider what an individual firm free to choose would want to do if all other firms had committed themselves to the forced-liquidation code $L O$. If this one firm could commit itself to the menu code $L R$, the best way to do so would be to take on debt of 0.550 (more than the 0.5 that its peers are choosing). It would then liquidate if its value later turned out to be below 0.433, and reorganize if its value turned out to be between 0.433 and 0.550 . The value of this firm would be 0.6208 , less than the 0.625 that other firms are worth. Thus, firms would not deviate (to the $L R$ menu) if its peer had committed themselves to forced liquidation $L O$. When each other firm has committed itself to a forced-liquidation code, then every single firm indeed remains trapped in this $L O$ equilibrium.

Figure 7 generalizes this example starting with the same base values. If the benefits of debt are too low, firms choose little or no debt in either distress procedure. Hence, there is no advantage to mandating the menu code. Firms are better off in a liquidation-only code. If the benefits of debt are too high, firms do not choose high or maximum debt in either distress procedure, nor is there an advantage to mandating the menu. Firms could contract into the menu code. Figure 7 shows that there is an intermediate region over which firms are collectively better off if the government institutes a mandatory menu code. Because the region is intermediate and because parameters typically impact both the left and the right limit, there are no easy-to-interpret comparative statics where a no-opt-out bankruptcy menu code is better than a voluntary forced-liquidation code.

One parameter, kappa, is especially interesting, because it parameterizes the fire-sale externality. It has a non-monotonic impact on the chamber-of-commerce condition. Figure 7 shows that as kappa increases from 0 , the externality becomes stronger and the value of 
collective action increases. However, beyond some threshold, higher kappas result in lower debt and therefore fewer in-equilibrium liquidations and the value of collective action decreases.

\section{Context}

Our model was designed to illustrate the argument that there can be parameter regions in which a forced ex-post menu choice can reduce in-equilibrium liquidations, with its negative fire-sale externalities (and do so in a way that is better than outright prohibition of liquidation). This qualitative conclusion is robust to reasonable alternative assumptions, although the quantitative parameter regions where the mandatory menu is superior would change. For example:

- In the model, we assumed that the value of the remaining firms was unaffected by liquidations. If the continuation value of remaining firms increased linearly in alpha, then liquidating firms would generate a positive externality. As long as this externality does not outweigh the negative firesale externality, the model's algebra would remain the same (only the $\kappa$ parameter would change) and our conclusions would hold. If we introduce a value increase that is non-linear in alpha, at some point, the value of reorganization could exceed the value of liquidation. This could create an equilibrium in which, in the absence of government intervention, the fraction of firms liquidating

could be less than 1 . The value of firms in this equilibrium would then have to be compared to the value of firms if all were forced into the menu code.

- In the model, we assumed a uniform distribution on value realizations. The model becomes more difficult to solve if we assume alternative distributions, but there is no reason to believe it would alter the essential insight that the menu code can reduce the fraction of firms liquidating in equilibrium relative to a forced-liquidation code.

- In the model, the law of large numbers implied that there was no uncertainty in the frequency of outcomes. With risk-neutral firms, the results would not change.

- In the model, the liquidation price $L-\kappa \cdot \alpha$ was entirely independent of the continuation value $V$. If the liquidation value increases with the continuation value, too, then the model becomes more complex but remains qualitatively the same. The slope of the liquidation value would then be lower than it is when the firm continues (e.g., $L-\kappa \cdot \alpha+\psi \cdot V$, where $\psi \ll(1+\phi))$. As $\psi \rightarrow 0$, this model turns into the one 
we presented. From a conceptual perspective, our model should be considered as assuming that the liquidation value is less sensitive to the unencumbered asset value than the reorganization value.

- In the formal model, it was optimal under some parameters to force all firms to have a menu in distress. More broadly, our model has shown that the economic forces considered (liquidation externalities in the presence of modest agency costs) can imply that the cost of a forced menu are not as great as previously imagined. In the extreme version of this argument, our model is not even inconsistent with the view that the forced-menu code has survived partly because many or all firms would have chosen the same menu contract by themselves. ${ }^{16}$ The relative-cost argument makes the existing U.S. code less of a puzzle.

Moreover, even if the U.S. code is not optimal, by mitigating the code's shortcomings, these forces could have helped to maintain it. This is the case even when other economic forces or even non-economic considerations were at work in shaping the code, too.

\section{A Renegotiation with a Menu Procedure for Resolving Distress}

In the model, we assumed that the manager's incentives differed from those of the firm by the exogenous parameter $\beta .{ }^{17}$ Managers continued when

$$
\overbrace{V-\phi \cdot(D-V)}^{\text {Reorg Value }}+\overbrace{\beta}^{\text {Bias }}>\overbrace{L-\kappa \cdot \alpha}^{\text {Liq Value }} .
$$

Managers preferred to continue too often. If firms could align the incentives of their manager better with their own, the firms would then be ex-ante in better positions to choose the procedure for themselves. However, unless the firm could completely sell itself to the manager, the effect of ex-post renegotiation would merely be a smaller parameter $\beta$. Handing the managers extra equity (i.e., a "bribe" to tilt more towards liquidation when liquidation is optimal) is costly for the creditors in possession.

\footnotetext{
${ }^{16}$ Geometrically, the region next to the self-chosen menu is the region with the forced menu. If/when parameters shift modestly, the optimal code would shift from a voluntary menu to the forced menu.

${ }^{17}$ Our parameter $\beta$ also proxies for over-continuation due to a holdup game between creditors and shareholders that we have not explicitly modelled, but that is generally acknowledged to be of importance in financial-distress proceedings.
} 
We now show that our model conclusions hold when owners-in-possession can bribe managers to make better decisions. We model this as a take-it-or-leave-it payment $x$ from owners to managers if the managers liquidate. This payment reduces the managerial preference to continue too often but reduces what is left for the creditors in possession. The payment reduces the liquidation value and flows directly to the manager. Because accepting a bribe and liquidating can have longer-term reputational consequences, we introduce a parameter $\psi$. The parameter $\psi$ represents the weight the management places on investor cash flow and $(1-\psi)$ represents the weight the manager places on their private benefits. Put differently, $\psi$ measures the relative managerial preference for a bribe.

Management now continues when

$$
\psi \cdot\left[V-\phi \cdot\left(D^{\prime}-V\right)\right]+(1-\psi) \cdot \beta>\psi \cdot\left(L-\kappa \cdot \alpha^{\prime}-x\right)+(1-\psi) \cdot x
$$

where the prime indicates that the $\alpha^{\prime}$ and $D^{\prime}$ are different from those in our base model. The indifferent firm changes from $\bar{V}=\left(L-\kappa \cdot \alpha^{\prime}+\phi \cdot D^{\prime}-\beta\right) /(1+\phi)$ to

$$
\widehat{V}(x)=\frac{L-\kappa \cdot \alpha^{\prime}+\phi \cdot D^{\prime}+x \cdot(1-2 \cdot \psi) / \psi-\beta \cdot(1-\psi) / \psi}{1+\phi} .
$$

We solve the model by backward induction. At time 1, management learns their firm's productivity $V_{i}$. Firms are competitive. Therefore, they take the price of liquidated assets, $L-\kappa \cdot \alpha^{\prime}$, as given. If $V_{i} \leq D^{\prime}$ the firm defaults on its debt obligations and the firm (now the bondholders) make a take-it-or-leave-it offer to pay $x$ to the decision-makers (the managers and shareholders) if the firm is liquidated. The managers accept the offer because it makes them at least as well off as they would be in the absence of renegotiation.

In the event of default, the bondholders know that $V_{i}$ is distributed uniformly on the interval $\left[0, D^{\prime}\right]$, but they do not know the realized value of $V_{i}$. Furthermore, the bondholders understand that management liquidates for all $V_{i} \leq \widehat{V}(x)$. They choose the optimal transfer $x$ to maximize their own payoffs at time 1

$$
\max _{x} \frac{1}{D^{\prime}} \cdot \int_{0}^{\widehat{V}(x)}\left(L-\kappa \cdot \alpha^{\prime}-x\right) \mathrm{dV}+\frac{1}{D^{\prime}} \cdot \int_{\widehat{V}(x)}^{D^{\prime}}\left[V-\phi \cdot\left(D^{\prime}-V\right)\right] \mathrm{dV} .
$$

This implies

$$
x^{*}=\frac{(1-\psi)^{2} \cdot \beta-\psi^{2} \cdot\left(L-\kappa \cdot \alpha^{\prime}+\phi \cdot D^{\prime}\right)}{1-2 \cdot \psi},
$$


and, therefore,

$$
\widehat{V}^{*}\left(D^{\prime}\right)=\frac{(1-\psi) \cdot\left(L-\kappa \cdot \alpha^{\prime}+\phi \cdot D^{\prime}-\beta\right)}{1+\phi} .
$$

This can be used to show that renegotiation mitigates but does not eliminate management's incentive to continue too often in distress:

Proposition 3 If $x^{*} \geq 0$ then $\widehat{V}^{*}\left(D^{\prime}\right) \leq V^{*}\left(D^{\prime}\right)$, where $V^{*}\left(D^{\prime}\right)=\left(L-\kappa \cdot \alpha^{\prime}+\phi \cdot D^{\prime}\right) /(1+\phi)$ is the efficient continuation threshold.

With renegotiation at time 1 , management still has an incentive to continue too often. This creates a robust region in which our three equilibrium conditions for the optimality of a forced menu contract continue to hold.

The equilibrium renegotiation at time 1 changes the optimal debt choice at time 0 . Firms are competitive and thus take the price of liquidated assets at time 1 as given. The objective at time 0 is to choose debt $D^{\prime}$ to maximize firm value

$V\left(D^{\prime}\right) \equiv \frac{1}{\gamma} \cdot\left\{\int_{0}^{\widehat{V}^{*}\left(D^{\prime}\right)}\left(L-\kappa \cdot \alpha^{\prime}\right) \mathrm{dV}+\int_{\widehat{V}^{*}\left(D^{\prime}\right)}^{D^{\prime}}\left[V-\phi \cdot\left(D^{\prime}-V\right)\right] \mathrm{dV}+\int_{D^{\prime}}^{\gamma} V \mathrm{dV}\right\}+\lambda \cdot D^{\prime}$.

There is a unique symmetric equilibrium in which $\alpha^{*^{\prime}}$ and $D^{*^{\prime}}$ are determined by

$$
\begin{gathered}
D^{*^{\prime}}=\frac{\left(L-\kappa \cdot \alpha^{*^{\prime}}\right) \cdot\left(1-\psi^{2}\right)-\beta \cdot \psi \cdot(1-\psi)+\lambda \cdot \gamma \cdot(1+\phi) / \phi}{\left(1+\phi \cdot \psi^{2}\right)}, \\
\alpha^{*^{\prime}}=\widehat{V}^{*}\left(D^{*^{\prime}}\right) / \gamma .
\end{gathered}
$$

Substituting $\alpha^{*^{\prime}}$ and $D^{*^{\prime}}$ into the objective gives the value $V^{*^{\prime}}$. This can then be used to check the conditions for the optimality of the forced-menu contract over the laissez-faire choice. Using the same parameter values as those in Figure 7, Figure 8 plots the region in which

1. Firms are collectively better off if all firms are committed to the forced-menu contract;

2. Individually, firms would prefer to deviate from a laissez-fare equilibrium if all other firms have committed to the forced-menu contract;

3. Individually, firms would not be better off deviating from an equilibrium in which all firms liquidate. 
The red area in Figure 8 is where the forced-choice region is better for firms than the laissez-faire solution. With better-aligned incentives, the region in which creditors are better off with government-legislated coordination support than they would be on their own is necessarily smaller (and different), but continues to be robust.

\section{B Related Literature}

Our paper builds on the long literature that shows how and when forced prohibitions can improve social welfare.

The first strand was based on asymmetric information. Arrow (1973, p210) pointed out that if higher education serves as a filter of skills, then social welfare may increase if higher education is abolished. Aghion and Hermalin (1990) and Spier (1992) develop this further to explain how unproductive signaling can explain constraints on permissible punishments. ${ }^{18,19}$

The second and more recent strand was based on externalities on non-contracting parties that cause a "tragedy of the commons" (Hardin (1968)). Wickelgren (2005) shows how individual customers would like to waive product liability, but the effect of the waiver would be to their joint (product-safety) detriment. Bond and Newman (2009) consider similar prohibitions on permissible punishments as Aghion-Hermalin and Spier, but argue that crippling punishments in case of failure would deprive other parties of future trading surplus with the sanction victims. von Lilienfeld-Toal and Mookherjee (2010) extend this argument further by showing how prohibitions on failed-borrower punishments can reduce the in-equilibrium profitability of lenders (relative to borrowers), and thus draw more votes by borrowers. The "capture" perspective could also be consistent with a view that Chapter 11 exists to make financing more difficult, which could then restrict competitive entry (e.g., as in Aghion and Bolton (1987)). ${ }^{20}$

\footnotetext{
${ }^{18}$ Although our own model satisfies these three conditions even in the absence of asymmetric information, these signaling concerns could further strengthen the argument. When creditors cannot assess firms' prospects as well as the borrowers can, then firms would engage in a "race to the bottom" where all but the very worst firms would signal their confidence by committing to a punishing liquidation procedure. The all-Chapter 7 equilibrium could "trap" firms (the second condition), whereas an all-Chapter 11-equilibrium could not exist (the third condition). However, to complete our explanation, such a model would still have to satisfy the first condition that the "with ex-post menu choice" code is preferable either to an all-Chapter 7 or an all-Chapter 11 code.

${ }^{19}$ Conversely, Anderlini, Felli and Postlewaite (2010) show how voiding contracts can improve welfare by preventing an inefficient pooling equilibrium instead of an inefficient separation.

${ }^{20}$ Note that we have not argued that the menu is necessarily socially optimal, but only stipulated that it is in the interest of the existing Chamber of Commerce to reduce fire sales. Even in our context, the menu
} 
Our paper's innovation was to illustrate not when a later choice should be prohibited, but when a later choice should be mandatory. Ex-post choice would not be the laissez-faire outcome, but the government-forced outcome. It is the menu with its mandatory "nonrepudiable" mandatory choice that helped to reduce a social externality. Whereas arguments similar to those put forth in prior literature could have suggested why a bankruptcy code should disallow Chapter 7 liquidation (or let firms contract out of liquidation), these arguments would not immediately have translated into an argument in favor of the presence of the menus (i.e., the mandatory later choices). This choice innovation was particularly relevant in the context of the U.S. bankruptcy code, where the inability of firms to choose their own contract (e.g., to commit to liquidation) has been a long-standing puzzle (Che and Schwartz (1999), Baird (1998)). However, the argument is broader than the context.

Non-alienable rights that cannot be contracted away are at the core of many economic and non-economic arrangements, and some may be well-suited to an analysis similar to that in our own model. It would be interesting to contemplate not only when a choice should be outright prohibited, but also when one should and when one should not leave later choices to contracting parties upfront. For example, whereas the Arrow (1973) model recommended the abolition of higher education, a model analogous to ours could suggest cases when a "handicapped" choice may be better. For example, whereas Spier (1992) and Bond and Newman (2009) can help explain the abolition of debtors' prisons, a model analogous to ours could help explain why parties cannot contract around fraud. There may be even broader applications, too. For example, most corporate charters and political constitutions do not allow electing individuals for life, but mandate regular elections. Individuals are not allowed to contract away their future choice of where to work.

Such modeling analysis is more productive when the challenge is to offer a positive explanation of a mandatory choice that has already been adopted in the real world. After all, our model had not only parameter values in which the mandatory menu was better, but also parameter values in which it was worse. (Any model or view of the world in which there would not also be parameter regions in which it is better to let firms decide by themselves would be absurd.) Our model is not normative: this would require consideration of all obvious alternative mechanisms. In our case, one alternative would be Pigouvian taxes on debt contracts that included forced-liquidation clauses (although they would be difficult to calibrate), possibly Pigouvian taxes on liquidation itself, constraints on or more taxation of corporate debt, or even facilitated coordination among creditors (such as a central bank

could well be a mechanism of firms and creditors to capture surplus that would otherwise go to third parties that specialize in liquidating. 
that lends to all firms and can itself decide ex-post when to reduce and when to encourage liquidations in the aggregate). Such comprehensiveness is beyond any economic model.

Finally, note that our argument can be viewed as suggesting why firms and their creditors have not lobbied strongly against the current U.S. bankruptcy code. For this argument, it is not even necessary that the no-opt-out code was deliberately created to reduce inequilibrium liquidation. It is sufficient to recognize the effects that its mandatory menu choice has created.

Our paper's key contribution was to show that the existing Code's forced-menu choice can remedy future, modestly sized liquidation externalities. If the liquidation externalities are too small, then there is no use for government intervention. They can choose what is best for them (either Chapter 7 or Chapter 11). If the liquidation costs are too large, firms can and will decide in favor of the menu contract themselves. The parameter region in which the externality makes the forced menu contract better than the voluntary contract are intermediate-they appear when there are both liquidation externalities and moderate agency costs. The region is not obscure but appears naturally.

\section{An Application of No-Opt-Out in Preference Law}

In our model, there is an outcome-a free ex-post choice of bankruptcy procedure-that is best for firms (the Chamber of Commerce condition) that firms would not reach under free contracting, even under the conditions under which free contracting is often thought to be optimal. Hence, a mandatory rule mandating a free ex-post choice could improve firms' welfare.

Yet, bankruptcy codes in the U.S. and elsewhere have many mandatory rules. It is an obvious question whether similar models can be used more generally. Are there other welfare improving equilibria that parties (the debtor and creditors) could not reach under free contracting? Do the mandatory rules that now exist mandate such equilibria? We cannot discuss all bankruptcy rules in general, but we can show informally that mandatory rules could well have another important application into what the law calls "voidable preferences." The analysis is similar to that above because it focuses on the welfare improving ex-post state, but it differs from that above because the U.S. bankruptcy Code's relevant mandatory rule restricts the debtor's ex-post freedom rather than preserves it. The 
Code prohibits the insolvent debtor's payment of preferences. Instead, it may be the case that a code could enhance welfare if it instead preserved the debtor's freedom to pay them.

We begin with a brief description of the law. A "general creditor"-a creditor whose claim is not protected with a mortgage or a security interest-is paid pro rata. Letting $v$ be the value of the estate that is available for distribution to creditors and $d$ be the total debt the firm owes, under the pro-rata rule, each creditor is paid $v / d=a$ per dollar lent. Under insolvency, $a<1$. For example, if $v=\$ 100$ and $d=\$ 200, a=0.5$ and a creditor who is owed $\$ 20$ collects $\$ 10$. We focus on general creditors, because the preference law bears on them and because the reasons for taking security transcend the analysis here.

A "preference" is a payment to a general creditor made within 90 days of bankruptcy on account of a debt that was contracted before the payment was made. For example, there is a preference if a creditor lent $\$ 20$ on February 1, is repaid the $\$ 20$ on March 1 and the debtor files for bankruptcy on April 1. Bankruptcy law disfavors preferences largely because they subvert the pro-rata rule. In this example, after the preference is paid, $v=\$ 80$, $d=\$ 180$ and $a$ falls to 0.44 . The creditor who is owed $\$ 20$ now collects $\$ 8.80$. There is no penalty for paying or receiving a preference, but the bankruptcy trustee can recover the preference and add it to the bankrupt estate. If the the trustee recovers the preference in this example, $a$ is raised to 0.5: the estate now is worth $\$ 100$ and the debt increases to $\$ 200$. Our illustrative creditor again collects $\$ 10 .^{21}$

The efficiency concern with current preference law is that permitting the trustee (or debtor in possession) to recover preferences actually reduces the value of the total estate that can be distributed to creditors. There is an ex-ante version of this concern: the less the debtor can promise to creditors in the insolvency state, the higher is the interest rate, and the fewer positive NPV projects firms can finance. We explain this concern by considering two insolvency scenarios.

In the first insolvency scenario, the debtor recognizes that liquidation under Chapter 7 is the only possible bankruptcy outcome. The owner/managers would then not necessarily be indifferent to how the firm's value is distributed, but instead they may actually care. For

\footnotetext{
${ }^{21}$ Bankruptcy scholars sometimes argue that permitting preferences would be undesirable because creditors then would demand them, with the result that debtors may be prematurely liquidated. This argument is unpersuasive because the debtor can refuse to pay, thereby requiring the creditor to sue. Contract actions take a long time to decide so the recalcitrant debtor has maneuvering room. The other popular justification advanced for preference law is that "fairness" requires every creditor to be paid the same amount per dollar lent ( $a$ times the debt). Because creditors are firms that can price risk, this argument is without philosophical support.
} 
example, a manager may want to pay a supplier in full if the manager believes that the supplier may employ him after bankruptcy.

Preferences reduce the total value in this liquidation scenario, because they are collected at positive cost and then paid out again. Let the debtor repay $l \cdot v$ of its value to creditors in the 90-day period, where $0<l<1$. Not every preference is discoverable, so we assume that the trustee recovers back $b<l$ of this sum at a cost of $c(b)$. The total amount of the estate that is paid to creditors has not increased in consequence of the trustee's action. It is still $v$ because the debtor is to be liquidated. But now $v$ is disaggregated: ${ }^{22}$

$$
(1-b) \cdot l \cdot v+b \cdot l \cdot v+(1-l) \cdot v=v
$$

The net amount that is distributed, however, is $v-c(b)$. The result is that, when the debtor is to be liquidated, the preference law merely redistributes value among the creditors at positive cost.

In the second insolvency scenario, the debtor's managers believe that the firm will continue. The managers now have no incentive to pay "redistributional preferences," because creditors are entitled in bankruptcy only to their pro rata share. Hence, to pay more-to pay preferences-would dissipate needed cash. The managers of firms with positive expected continuation values thus want to pay only "value-increasing preferences." The common example is a payment to a favored supplier to signal credibly that the managers believe the debtor will survive and to create good will. Suppliers and customers are reluctant to deal with an insolvent on the same terms as a solvent firm could command: the insolvent firm is more risky. In one well-known case, ${ }^{23}$ the debtor asked the bankruptcy court to approve payment in full to a subset of suppliers with the condition that the suppliers deliver product on the same terms while the firm was in Chapter 11 and for a period thereafter as the suppliers had offered when the firm was solvent.

In the continuation scenario, the debtor pays preferences when the dollar outlay is less than the expected increase in estate value that those dollars create. The case for permitting such preferences is stronger than in the liquidation scenario: the trustee again would not incur collection costs and firm value would increase (on an expected basis). Nevertheless, the law bans these preferences as well because they are within 90-day payments.

\footnotetext{
${ }^{22}$ The first term on the LHS of this equality is represents the preference sums that creditors keep, but these discharge legitimate debts; the second term is the preference sums the trustee recovers for the estate; the third term is the fraction of the estate that was not paid out as preferences.

${ }^{23}$ In re Kmart Corp., 359 F.3d 866 (7th Cir. 2004). The appellate court disallowed the payments.
} 
Thus far, we have argued that borrowers as a group would be better off if the law relaxed the ban on preference payments. Our model suggests that the law could go further, however, to permit insolvent debtors to pay preferences and to prevent parties from contracting out of a "preferences permitted" world in lending agreements.

Suppose first that the law permits preferences to be paid in the liquidation scenario. Denote the face value of a representative creditor's debt as $d_{i}$. The creditor's expected payoff $\pi$ is the probability that it will be preferred-be paid in full-plus the probability that it will be paid pro rata from the remaining estate after the debtor has paid preferences to others. Hence, $\pi<d_{i}$. If every other creditor accepted a preferences-permitted default, this creditor would have an incentive to write a debt contract that prevented the debtor from paying preferences. This would be the equivalent of a covenant that governed the creditor's behavior. A covenant cannot be enforced against non-parties, so the debtor could violate it by paying preferences to others. Rather, a covenant is enforced (good will penalties aside) by acceleration: the creditor whose covenant is breached is entitled to declare the entire debt payable at once. Then the creditor can sue and attach assets (see Ayotte and Bolton (2011) and Schwartz (1996)).

Therefore, if every other creditor accepted the preferences-permitted default, the representative creditor would defect to a contract that banned the payment of preferences. If the debtor began to pay preferences to others, the defecting creditor would be entitled to demand payment in full and likely would receive it: there is commonly enough money to pay one agent. And if the debtor paid no preferences, the creditor would get his pro-rata payoff. Hence, the defecting creditor would increase its expected payoff above $\pi$ with a contract that banned preferences because this creditor would have a higher probability of being paid in full and a higher downside: the pro-rata payoff undiminished by the payment of preferences. A preferences-permitted default thus would fall prey to the instability condition: it would vanish in equilibrium.

Now consider a default that banned preferences. If every other creditor adhered to the default, the representative creditor would not have an incentive to defect to a contract that permitted the debtor to pay preferences. Under such a contract, the debtor would be permitted to prefer whom it pleased. Hence, the contract would not materially increase the probability that the creditor would be paid in full, but it would reduce the creditor's pro rata payoff because the estate would be diminished by the preferences the debtor pays to others. Hence, a default that banned preferences would satisfy the stability condition: creditors would be trapped in a no-preferences-permitted world. The same logic would apply in the continuation scenario, in which the debtor would want to pay value-increasing 
preferences. A creditor who does not expect to receive such preferences would still be better off defecting from a preferences-permitted default. The debtor would likely breach the defecting contract by paying preferences. Because these would increase the value of the estate, the defecting creditor would have a higher probability of being paid in full. And the creditor would accept a no-preferences default, because otherwise the creditor would be benefitting others than itself.

In the analysis above, the Bankruptcy Code's mandatory procedural choice rule preserves the debtors' ex-post freedom to act. In the analysis here, the Bankruptcy Code's preference rule restricts the debtor's ex-post freedom to act. Intuitively, our model could thus suggest that there is a class of mandatory rules in bankruptcy contexts that either do or could desirably protect the debtor's discretion to act when insolvent.

\section{Conclusion}

Laissez faire is the freedom to decide. But in real life, it is not unfettered. There are many laws that prevent self-proscription. Our paper has shown that it is possible that such prohibitions against a choice today in order to preserve a choice tomorrow can make sense. A universal no-opt-out law can sometimes be better than one in which the parties themselves can decide (including deciding today to allow themselves choice in the future).

Such an argument has allowed our paper to resolve a long-standing conceptual key puzzle in the theoretical bankruptcy literature (Che and Schwartz (1999), Baird (1998)): why have firms not been allowed to choose their own financial distress resolution procedures; or, alternatively, why has there been so little organized resistance against the existing forcedmenu U.S. bankruptcy code? Why does the U.S. bankruptcy code always preserve the firm's choice between Chapter 7 liquidation and Chapter 11 reorganization? Our paper has shown that if agency costs are too large, it is better to allow firms to commit themselves to liquidation. If agency costs and/or externalities are too small, firms can write (menu) contracts themselves and there is no need for coercion. However, if agency costs are intermediate, then the universal U.S. prohibition on free contracting can help reduce firesale liquidation externalities in equilibrium in a way that is better than what the parties could accomplish by themselves.

Our paper's primary goal was to provide a possible positive explanation for the existing U.S. Code. It was not to offer better codes. For example, the government might want to calibrate bankruptcy rules to specific industries or even specific firms. However, this would 
be pushing the economic analysis of the bankruptcy code, including our own model, too far. Moreover, excessive flexibility in the bankruptcy code could itself become expensive. A more modest interpretation of our model is that it has merely suggested that the forced-menu U.S. Bankruptcy Code need not be as bad as previously presumed, relative to a contracting code that would allow firm and creditors to commit to a menu voluntarily.

There is also a large and growing empirical law-and-finance literature, pioneered in La Porta, Lopez de Silanes, Shleifer and Vishny (1998). Admittedly, it is difficult to test law-and-finance theories over short time-frames, because laws do not change quickly in response to changing circumstances.

One possible set of tests could focus on the role of creditor coordination. For example, Davydenko and Franks (2008, page 592) describe how U.K. banks established a centralized management structure for the liquidation of distressed firms in the early 1990s in order to improve coordination among their different branches. They argue that this was feasible because of the more oligopolistic market structure of U.K. banking. For another example, Germany has also recently moved towards a U.S. style debtor-friendly code. This is not inconsistent with a view that when just a few large banks held most of the ownership of German corporations, these banks would have benefited less from government intervention: they could have more easily coordinated by themselves. As the German financial markets broadened and creditors became more diffuse and less coordinated, the forced-menu code became relatively better. The forced menu would have reduced the negative externalities that firms and their creditors would have ignored if left to their own (now less coordinated) devices.

Another possible set of tests could attempt to measure the parameters of the model more directly. A researcher could estimate when firms would not only be privately but also collectively better off if they could commit to liquidate in financial distress. It is only in those cases in which the forced-menu contract would hurt them. The key implication here would be that forced menu codes appear more often when agency costs are intermediate and fire sale externalities are large. It would also be possible to examine whether particular industries - with externalities and non-extreme agency costs-would lobby more in favor of a forced no-opt-out code. Swedish-style liquidation-only codes should only become more prevalent in industries and countries in which agency costs are exceedingly large. Naturally, such a "value test" of the model would be decidedly more challenging for an empiricist than the "coordination test." 


\section{References}

Aghion, Philippe and Benjamin Hermalin, "Legal Restrictions on Private Contracts Can Enhance Efficiency," Journal of Law, Economics, and Organization, Autumn 1990, 6 (2), 381-409.

and Patrick Bolton, "Contracts as a Barrier to Entry," American Economic Review, June 1987, 77 (3), 388-401.

Anderlini, Luca, Leonardo Felli, and Andrew Postlewaite, "Should Courts Always Enforce What Contracting Parties Write?," Technical Report, Georgetown University and London School of Economics and University of Pennsylvania October 2010.

Arrow, Kenneth J., "Higher education as a filter," Journal of Public Economics, 1973, 2 (3), 193-216.

Ayotte, Kenneth and Patrick Bolton, "Optimal Property Rights in Financial Contracting," The Review of Financial Studies, 2011, 24, 3401-3433.

Baird, Douglas, “Bankruptcy's Uncontested Axioms," Yale Law Journal 573, 1998, 108, 576-579.

Bond, Philip and Andrew F. Newman, "Prohibitions on punishments in private contracts," Journal of Financial Intermediation, 2009, 18, 526-540.

Che, Yeon-Koo and Alan Schwartz, "Section 365, Mandatory Bankruptcy Rules and Inefficient Continuance," Journal of Law, Economics and Organization, July 1999, 15 (2), 441-67.

Davydenko, Sergei A. and Julian R. Franks, "Do Bankruptcy Codes Matter? A Study of Defaults in France, Germany, and the U.K.," The Journal of Finance, April 2008, 63 (2), 565-608.

Decamps, John-Paul and Antoine Faure, "Excessive Continuance and the Dynamic Agency Costs of Debt," European Economic Review, 2002, 46 (9), 1623-1644.

Hardin, Garrett, “The Tragedy of the Commons," Science, 1968, 162, 1243-1248.

La Porta, Rafael, Florencio Lopez de Silanes, Andrei Shleifer, and Robert W. Vishny, "Law and Finance," Journal of Political Economy, December 1998, 106 (6), 1113-1155.

Morrison, Edward R., "Bargaining around Bankruptcy: Small Business Workouts and State Law," The Journal of Legal Studies, 2009, 38 (2), 255-307.

Schwartz, Alan, "Bankruptcy Workouts and Debt Contracts," Journal of Law and Economics, April 1993, 36 (1), 595-632.

, "Priority Contracts and Priority in Bankruptcy," Cornell Law Review, 1996, 82, 1396-1419. 
__ "Contracting about Bankruptcy," Journal of Law, Economics, and Organization, 1997, 13 (1), 127-146.

Shleifer, Andrei and Robert Vishny, "Fire Sales in Finance and Macroeconomics," Journal of Economic Perspectives, 2011, 25 (1), 29-48.

_ and _ _ "Fire Sales in Finance and Macroeconomics," Journal of Economic Perspectives, 2011, 25 (1), 29-48.

Spier, Kathryn E., "Incomplete contracts and signalling," RAND Journal of Economics, Autumn 1992, 23 (3).

von Lilienfeld-Toal, Ulf and Dilip Mookherjee, “The Political Economy of Debt Bondage," American Economic Journal: Microeconomics, 2010, 2 (3), 44-84.

Wickelgren, Abraham L., "The Inefficiency of Contractually-Based Liability with Rational Consumers," Journal of Law, Economics, and Organization, 2005, 22 (1), 168-183.

\section{A Technical Appendix}

\section{A Proof of Proposition 2}

$f_{L O} \equiv 1-f_{L R}$ is the proportion of firms that choose to force liquidation in the event of financial distress, and suppose all firms conjecture that $\alpha$ proportion of all firms will be forced to liquidate. For the firms choosing forced liquidation, (4) showed that the optimal debt is

$$
D^{\llcorner O}(\alpha)=L-\kappa \cdot \alpha+\gamma \cdot \lambda
$$

For the firms choosing the menu, (9) showed that the optimal debt is

$$
D^{L R}(\alpha)=L-\kappa \cdot \alpha+\gamma \cdot \lambda \cdot(1+1 / \phi),
$$

which implies the threshold value $\bar{V}$ for liquidation

$$
\bar{V}(\alpha)=L-\kappa \cdot \alpha+\gamma \cdot \lambda-\beta /(1+\phi) .
$$


In equilibrium,

$$
\alpha\left(f_{\llcorner O}\right)=f_{\llcorner O} \cdot\left[\frac{D^{\llcorner O}(\alpha)}{\gamma}\right]+\left(1-f_{L O}\right) \cdot\left[\frac{\bar{V}(\alpha)}{\gamma}\right]
$$

Substituting the above expressions for $D^{L R}(\alpha)$ and $\bar{V}(\alpha)$ into this equilibrium condition yields the equilibrium proportion of firms liquidating,

$$
\alpha^{*}\left(f_{L O}\right)=\left[\frac{L+\gamma \cdot \lambda}{\gamma+\kappa}\right]-\left(1-f_{L O}\right) \cdot\left[\frac{\beta}{(1+\phi) \cdot(\gamma+\kappa)}\right] \text {. }
$$

We can now determine the equilibrium proportion of firms $f_{\text {Lo }}^{*}$ which choose to force liquidation in the event of financial distress. Our main result demonstrates that either all firms choose to force liquidation $\left(f_{L O}^{*}=1\right)$ or no firms choose to force liquidation $\left(f_{L O}^{*}=0\right)$ :

- If $[\beta /(\gamma \cdot \lambda)]^{2}>(1+\phi) / \phi$, then there exists a unique equilibrium in which all firms choose to force liquidation in financial distress $\left(f_{\llcorner O}^{*}=1\right)$.

- If $[\beta /(\gamma \cdot \lambda)]^{2}<(1+\phi) / \phi$, then there exists a unique equilibrium in which all firms choose to offer the menu (with the Chapter 11 reorganization choice) in financial distress $\left(f_{\text {Lo }}^{*}=0\right)$. This was stated right after the lemma.

- If $[\beta /(\gamma \cdot \lambda)]^{2}=(1+\phi) / \phi$, every choice is an equilibrium. This is a knife-edge case.

With proportion $f_{L O}$ choosing to force liquidation in the event of financial distress, the firms choosing forced liquidation have ex-ante values of

$$
V^{L O}\left(f_{L O}\right) \equiv \int_{0}^{D^{L O}}\left(L-\kappa \cdot \alpha^{*}\right) \cdot\left(\frac{1}{\gamma}\right) d V+\int_{D^{L O}}^{\gamma} V \cdot\left(\frac{1}{\gamma}\right) d V+\lambda \cdot D^{\llcorner O} .
$$

The derivative with respect to $f_{L O}$ is

$$
\begin{aligned}
& V^{\left\llcorner O^{\prime}\right.}=\left(\frac{1}{\gamma}\right) \cdot\left[-\kappa \cdot \alpha^{*^{\prime}} \cdot\left(L-\kappa \cdot \alpha^{*}\right)-\kappa \cdot D^{\llcorner O} \cdot \alpha^{*^{\prime}}+\kappa \cdot D^{\llcorner O} \cdot \alpha^{*^{\prime}}-\gamma \cdot \lambda \cdot \kappa \cdot \alpha^{*^{\prime}}\right] \\
& =-\left(\frac{1}{\gamma}\right) \cdot\left[\kappa \cdot \alpha^{*^{\prime}} \cdot\left(L-\kappa \cdot \alpha^{*}+\gamma \cdot \lambda\right)\right] \text {. }
\end{aligned}
$$


In contrast, the firms choosing the menu (with Chapter 11 -reorganization) have ex-ante values of

$$
\begin{aligned}
V^{L R}\left(f_{L O}\right) \equiv \quad & \int_{D^{L R}}^{\bar{V}}\left(L-\kappa \cdot \alpha^{*}\right) \cdot\left(\frac{1}{\gamma}\right) d V \\
+ & \int_{\bar{V}}\left[V-\phi \cdot\left(D^{L R}-V\right)\right] \cdot\left(\frac{1}{\gamma}\right) d V \\
& +\int_{D^{L R}}^{\gamma} V \cdot\left(\frac{1}{\gamma}\right) d V+\lambda \cdot D^{L R} .
\end{aligned}
$$

The derivative with respect to $f_{L O}$ is

$$
\begin{aligned}
& V^{L R^{\prime}}=\left(\frac{1}{\gamma}\right) \cdot\left[-\kappa \cdot \alpha^{*^{\prime}} \cdot\left(L-\kappa \cdot \alpha^{*}\right)-\kappa \cdot \alpha^{*^{\prime}} \bar{V}-\phi \cdot D^{L R} \cdot \kappa \cdot \alpha^{*^{\prime}}+2 \cdot \phi \cdot D^{L R} \cdot \kappa \cdot \alpha^{*^{\prime}}\right. \\
&=\left.+(1+\phi) \cdot \bar{V} \cdot \kappa \cdot \alpha^{*^{\prime}}-\phi \cdot\left(D^{L R} \cdot \kappa \cdot \alpha^{*^{\prime}}+\bar{V} \cdot \kappa \cdot \alpha^{*^{\prime}}\right)-\gamma \cdot \lambda \cdot \kappa \cdot \alpha^{*^{\prime}}\right] \\
&=-\left(\frac{1}{\gamma}\right) \cdot\left[\kappa \cdot \alpha^{*^{\prime}} \cdot\left(L-\kappa \cdot \alpha^{*}+\gamma \cdot \lambda\right)\right]
\end{aligned}
$$

Because $V^{L O}\left(f_{L O}\right)=V^{L R^{\prime}}\left(f_{L O}\right)$ for all $f_{L O}$, it follows that $V^{L O}\left(f_{L O}\right)-V^{L R}\left(f_{L O}\right)$ is constant for all $f_{L O}$. This makes the rest of the proof easy. There are three parameter regions:

Region 1: $V^{L O}(1)-V^{L R}(1)>0$ : In this case, there is a pure strategy equilibrium in which all firms choose to force liquidation in the event of financial distress. That is, if all firms choose to force liquidation, then no firm has an incentive to deviate and offer continuation (Chapter 11) provisions. Therefore, $f_{L O}^{*}=1$. This equilibrium is unique because (i) $V^{L O}(1)-V^{L R}(1)=V^{L O}(0)-V^{L R}(0)>0$ implies that firms would have an incentive to deviate when no firms choose to force liquidation $\left(f_{L O}=0\right)$, and (ii) $V^{L O}(1)-V^{L R}(1)=V^{L O}\left(f_{L O}\right)-V^{L R}\left(f_{L O}\right)>0$. Thus, there is no interior equilibrium where $f_{\llcorner O} \in(0,1)$.

Region 2: $V^{L R}(1)-V^{L O}(1)=V^{L R}(0)-V^{L O}(0)>0$ : In this case, there is a pure strategy equilibrium in which all firms choose the menu (with its Chapter 11 reorganization provision) in the event of financial distress. That is, if all firms choose to offer the menu, then no firm has an incentive to deviate and commit to forced-liquidation. Therefore, $f_{L O}^{*}=0$. This equilibrium is unique because (i) $V^{L R}(1)-V^{L O}(1)>0$ implies that firms would have an incentive to deviate when all firms choose to force liquidation $\left(f_{L O}=1\right)$, and (ii) $V^{L R}(1)-V^{L O}(1)=V^{L R}\left(f_{L O}\right)-V^{L O}\left(f_{L O}\right)>0$. Thus, there is no interior equilibrium equilibrium $f_{\llcorner o} \in(0,1)$.

Region 3: $V^{L R}(1)-V^{L O}(1)=V^{L R}\left(f_{L O}\right)-V^{L O}\left(f_{L O}\right)=0 \forall f_{L O}$ : In this knife-edge case all $f_{L O}$ are (weakly) equilibria. 
It is straightforward to show that $V^{L O}\left(f_{L O}\right)>V^{L R}\left(f_{L O}\right)$ if and only if $[\beta /(\gamma \cdot \lambda)]^{2}>$ $(1+\phi) / \phi$.

\section{B Parameter Restrictions}

We must impose parameter restrictions to ensure that all equilibrium quantities are interior. We will express these conditions in terms of the parameter $\lambda$.

\section{B.1 The Forced-Liquidation Code (LO)}

- From equation (6), the proportion of firms choosing to liquidate, $\alpha^{L 0}$, and the optimal debt choice, $D^{\perp 0}$, are both non-negative, because all determining parameters are non-negative.

- The probability $\alpha^{L 0} \leq 1$ requires $L+\gamma \cdot \lambda \leq \gamma+\kappa$. Equivalently,

$$
\lambda \leq \frac{\gamma+\kappa-L}{\gamma} .
$$

- $D^{\llcorner 0} \leq \gamma$ follows immediately from $\alpha^{\llcorner O} \leq 1$.

- We require $D^{\llcorner 0} \leq V^{\llcorner 0}$, so that the debt-to-value ratio is less than one. Because

$$
V^{\llcorner O}=\frac{\gamma}{2} \cdot\left[1+\left(\frac{L+\gamma \cdot \lambda}{\gamma+\kappa}\right)^{2}\right],
$$

$D^{\llcorner 0} \leq \gamma / 2$ is sufficient, which simplifies to

$$
\lambda \leq \frac{\gamma+\kappa}{2 \cdot \gamma}-\frac{L}{\gamma} .
$$

- We require that (i) $V^{L 0} \geq L-\beta$, so that firms don't choose to liquidate immediately; and (ii) $D^{L 0} \geq L-\beta$, so that all non-distressed firms choose to continue. However, because $D^{\llcorner 0} \leq V^{\llcorner 0}$, the requirement $D^{\llcorner 0} \geq L-\beta$ is sufficient, which simplifies to

$$
\lambda \geq \frac{(\gamma+\kappa) \cdot(L-\beta)-\gamma \cdot L}{\gamma^{2}} .
$$


- Collecting these results, the following parameter restriction on the benefit of debt, $\lambda$, in the case without reorganization is sufficient:

$$
\frac{(\gamma+\kappa) \cdot(L-\beta)}{\gamma^{2}}-\frac{L}{\gamma} \leq \lambda \leq \frac{\gamma+\kappa}{2 \cdot \gamma}-\frac{L}{\gamma} .
$$

\section{B.2 The Menu Code With Choice of Liquidation or Reorganization (LR)}

- From Lemma 3, the proportion of firms choosing to liquidate $\alpha^{L R} \leq \alpha^{L O} \leq 1$ under condition (A1).

- The probability $\alpha^{L R} \geq 0$ requires

$$
\lambda \geq \frac{\beta}{\gamma \cdot(1+\phi)}-\frac{L}{\gamma} .
$$

- From Lemma 3, the optimal debt choice $D^{L R} \geq D^{L O} \geq 0$ under condition (A1).

- The condition $D^{L R} \leq \gamma$ requires

$$
\lambda \leq \frac{\left[1-\frac{\beta \cdot \kappa}{\gamma \cdot(\gamma+\kappa) \cdot(1+\phi)}-\frac{L}{\gamma+\kappa}\right]}{\left[\frac{1}{\phi}+\frac{\gamma}{\gamma+\kappa}\right]} \equiv \lambda_{D} .
$$

- The condition $\bar{V} \in\left[0, D^{L R}\right]$ is satisfied, because (i) $\bar{V}=\gamma \cdot \alpha^{L R}$ so $\bar{V} \geq 0$ if and only if $\alpha^{L R} \geq 0$, and (ii) $\bar{V} \cdot \gamma \cdot \alpha^{L R} \leq D^{L R}$ from inspection of Lemma 3.

- We require $D^{L R} \leq V^{L R}$ so that the debt-to-value ratio is less than one. From Lemma 3, this condition implies an upper bound on the benefit of debt.

- We require (i) $V^{L R} \geq L-\beta$ so that firms do not choose to liquidate immediately, and (ii) $D^{L R} \geq L-\beta$ so that all non-distressed firms choose to continue. However, because $D^{L R} \leq V^{L R}$, condition (A1) is sufficient because $D^{L R} \geq D^{L 0} \geq L-\beta$.

- Collecting these results, we impose the additional sufficient parameter restriction on the benefit of debt, $\lambda$, in the case with reorganization:

$$
\frac{\beta}{\gamma \cdot(1+\phi)}-\frac{L}{\gamma} \leq \lambda \leq \min \left\{\lambda_{D}, \lambda_{V}\right\}
$$


B Tables and Figures Follow 


\begin{tabular}{llc}
\hline \multicolumn{2}{c}{ Exogenous Variables } \\
\cline { 2 - 3 } \\
\cline { 2 - 3 } & Max Value of the firm, $V \sim U[0, \gamma]$ & $\gamma>0$ \\
$L$ & Liquidation Value If No Other Firm Liquidates ${ }^{*}$ & $0<L \ll D$ \\
$\lambda$ & Proportional Benefit of Debt & $0<\lambda<1$ \\
$\kappa$ & Asset Specificity & $\kappa>0$ \\
$\phi$ & Proportional cost of debt overhang in Chapter 11 & $\phi>0$ \\
$\beta$ & Private benefit to continuing & $0<b<V$ \\
\hline
\end{tabular}

Endogenous Variables, Corporate Choice

\begin{tabular}{llc}
\hline$D$ & Debt Choice, before Value is Revealed* & $0<D \ll V$ \\
Meta-Choice & Distress Resolution: (1) with-optional-reorganization, or (2) forced liquidation \\
\hline
\end{tabular}

Endogenous Variables, Market-Determined

\begin{tabular}{|c|c|c|}
\hline$\alpha$ & Fraction of Firms Expected/Known To Liquidate* & $0<\alpha<D / \gamma$ \\
\hline \multicolumn{3}{|c|}{ Endogenous Variables and/or Government Choice } \\
\hline$f$ & Fraction of Firms Voluntarily Choosing Forced Liquidation & $0<f<1$ \\
\hline Meta-Choice & \multicolumn{2}{|c|}{ (1) Allow firms to contract themselves, or (2) Impose Chapter 11 on all firms } \\
\hline
\end{tabular}

Table 1: Variable Names And Restrictions

* Because $D$ and $\alpha$ are determined in the model, we are imposing additional conditions (described in Section B) to ensure that this turns out to be the case. 


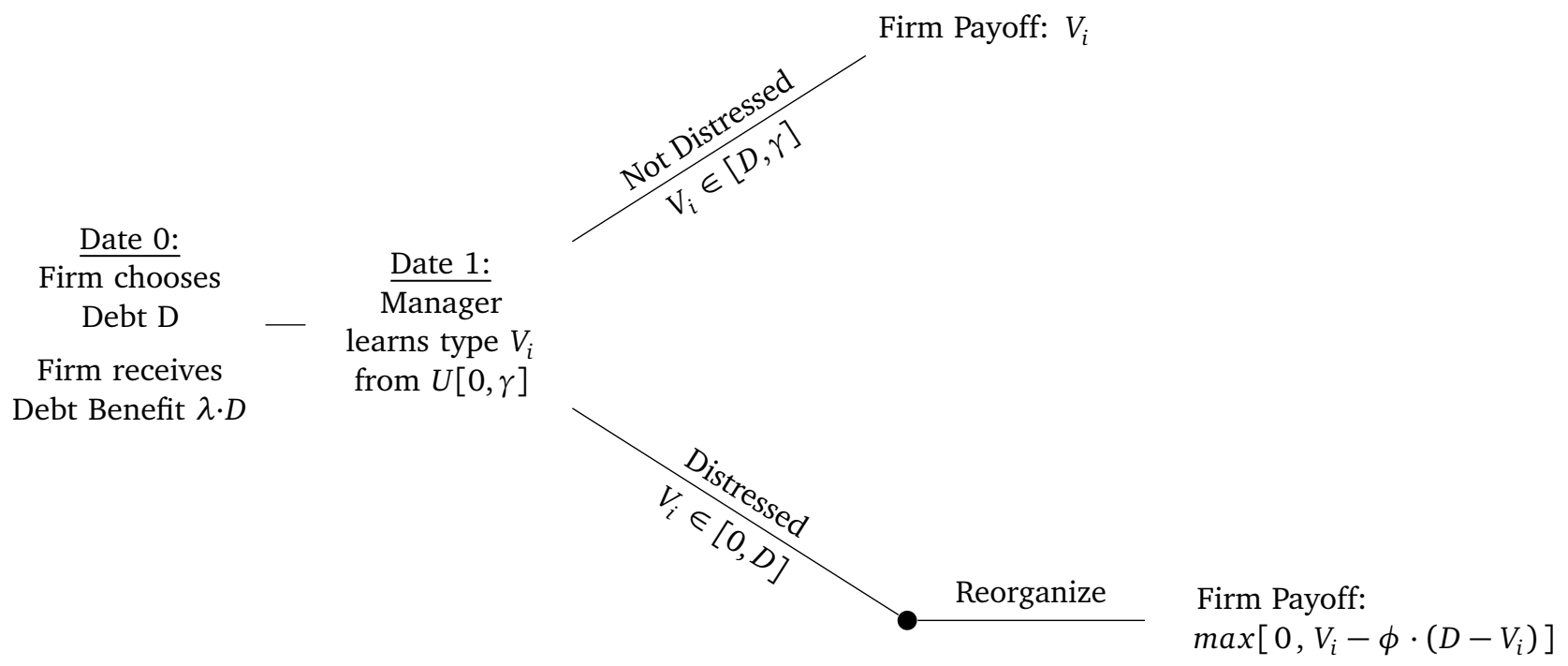

Figure 1: The Reorganization-Only Bankruptcy Code 


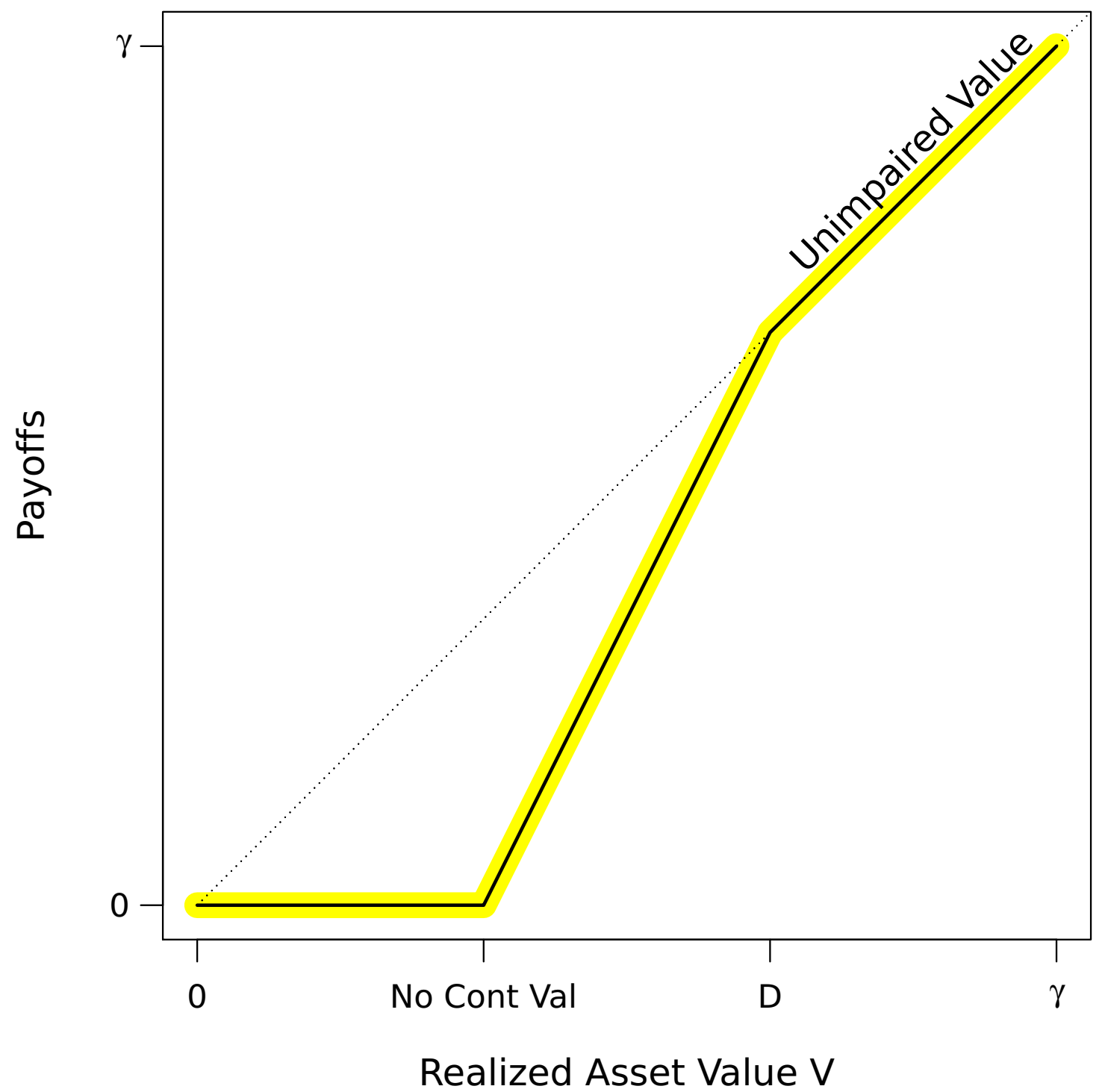

Figure 2: Debt-Contingent Payoffs in The Reorganization-Only Bankruptcy Code

Reorganization consumes a constant fraction of the debt shortfall of the firm. The firm creditors have free disposal. 
Date 0:

Firm chooses

Debt D

Firm receives

Debt Benefit $\lambda \cdot D$

Aggregation of D's

will determine $\alpha$
Firm Payoff: $V_{i}$

Date 1:

Manager

Learns Type $V_{i}$ from $U[0, \gamma]$

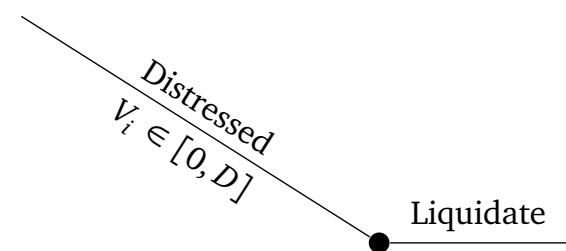

Firm Payoff: $L-\kappa \cdot \alpha$

Figure 3: The Liquidation-Only Bankruptcy Code 


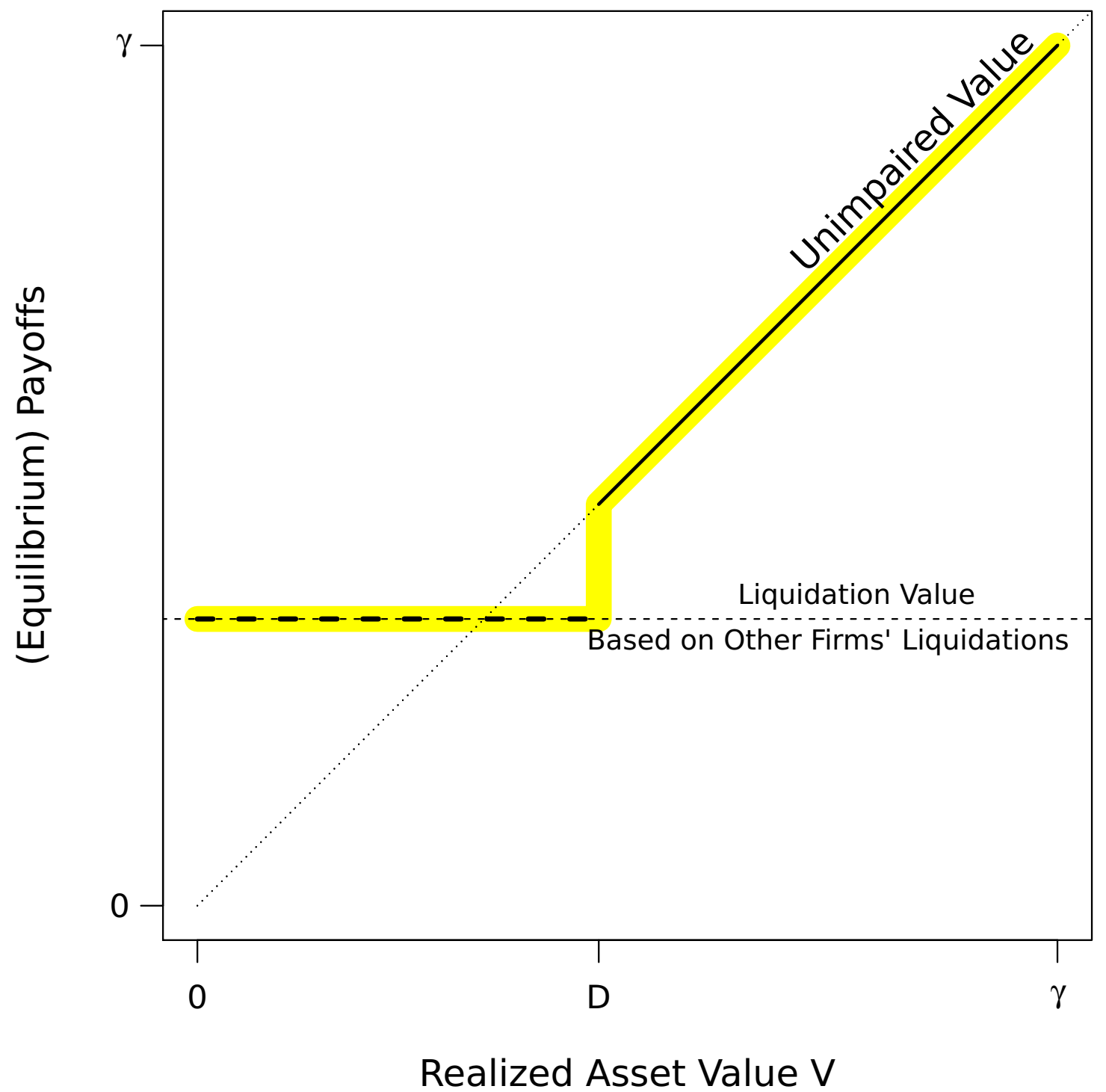

Figure 4: Debt-Contingent Payoffs in The Liquidation-Only Bankruptcy Code

Liquidation puts the assets to a completely different use. The value is determined by the fraction $\alpha$ of firms that are liquidating at the same time. 
Date 0:

Firm chooses

Debt D

Date 1:

Manager

Firm receives - Learns Type $V_{i}$

Debt Benefit $\lambda \cdot D \quad$ from $U[0, \gamma]$

Firm Payoff: $V_{i}$

Aggregation of D's

will determine $\alpha$
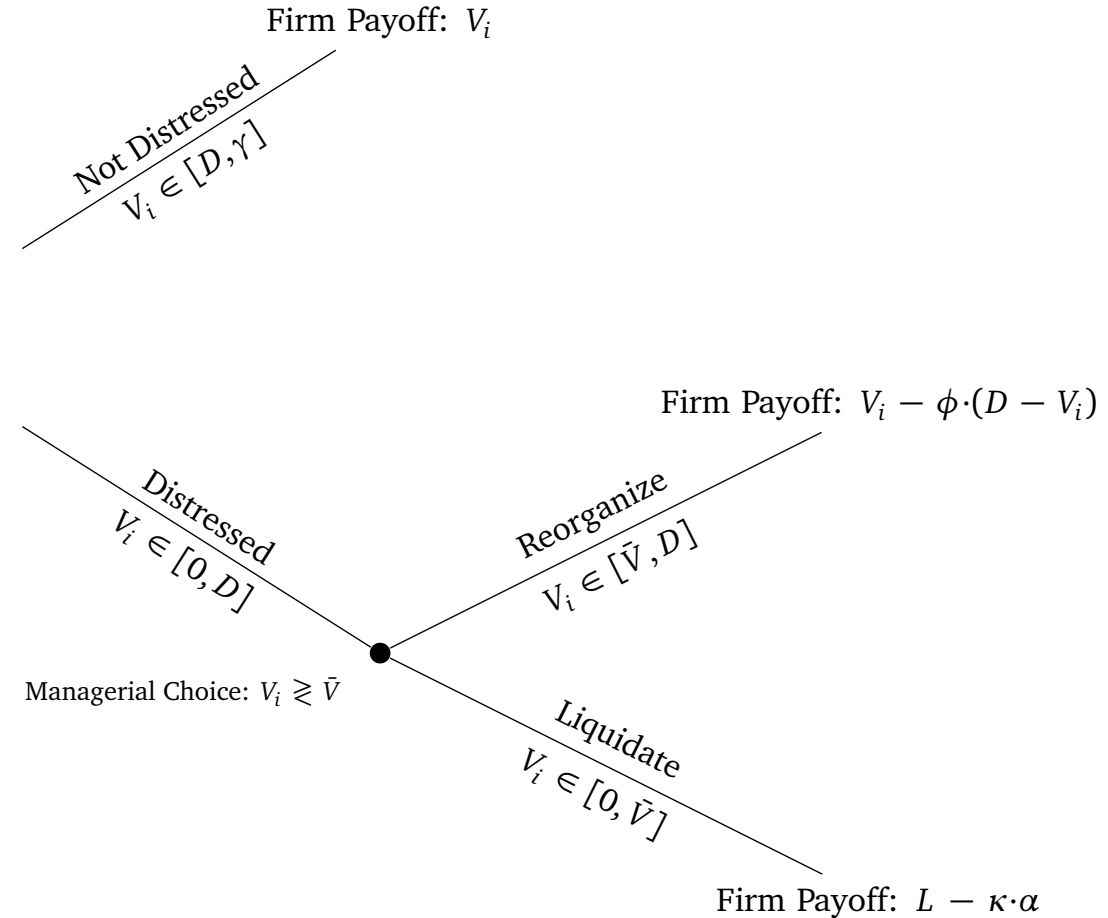

Figure 5: The Menu Bankruptcy Code 


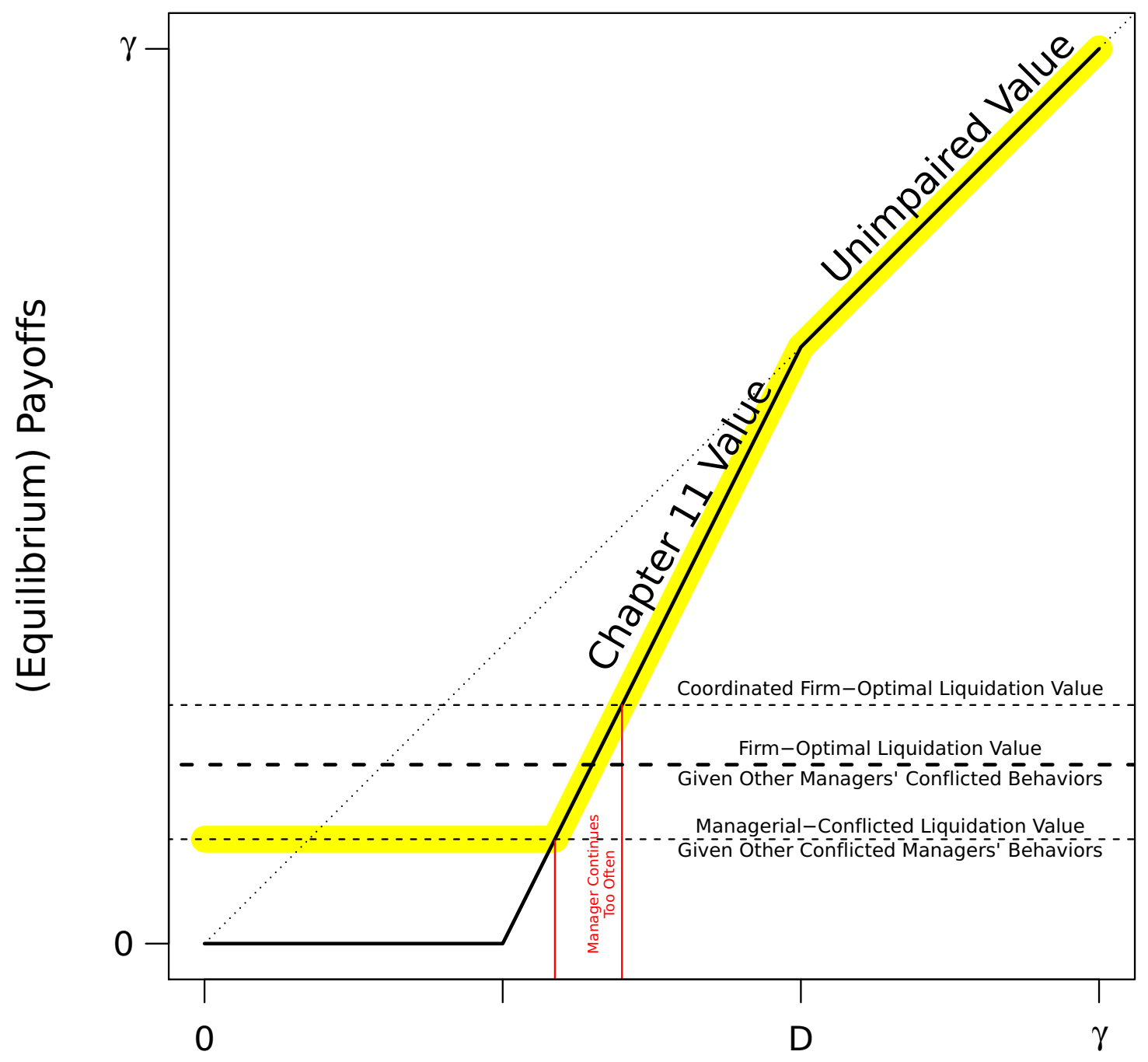

Realized Asset Value V

Figure 6: Debt-Contingent Payoffs in The Menu Bankruptcy Code

A bankruptcy menu allows firms to choose between reorganization and liquidation. Reorganization consumes a constant fraction of the debt shortfall of the firm. The firm creditors have free disposal. Liquidation puts the assets to a completely different use. The value is determined by the fraction $\alpha$ of firms that are liquidating at the same time and the firm's own debt choice. The bias of each firm to continue too often means not only that too many firms reorganize in equilibrium, but also that this firm reorganizes too often, given the (excessively large) number of firms reorganizing in equilibrium. 

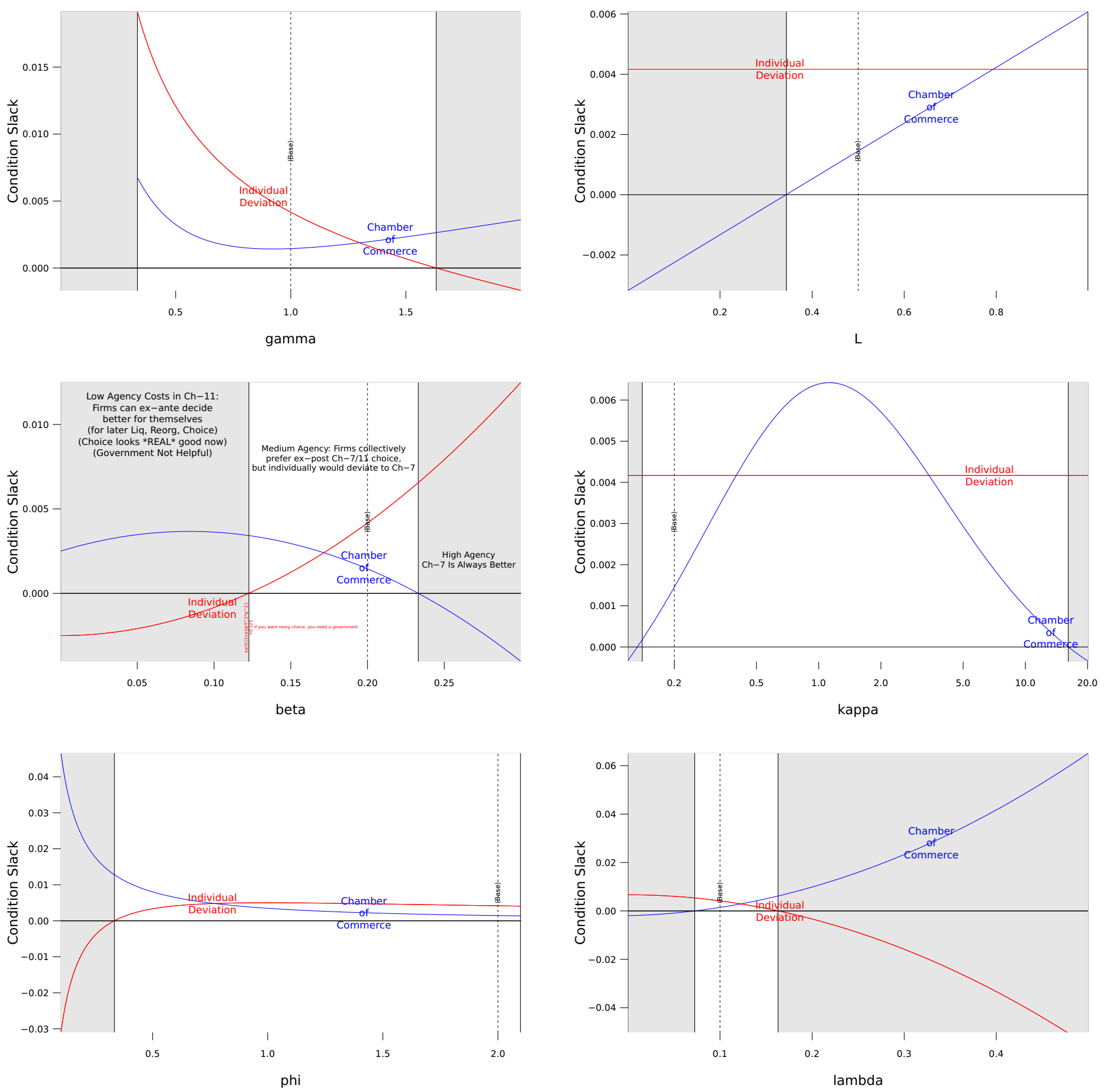

Figure 7: Condition Slack

These figures plot the slack in the chamber-of-commerce constraint (10), in blue, and the participation/incentive constraint (11), in red, that define the region where mandated ex-post choice is optimal. The base values are $\gamma=1, L=0.5, \lambda=0.1, \kappa=0.2, \phi=2$, and $\beta=0.2$. These are also the values for the numerical example in the text. 
Figure 8: Forced-Choice Code under Renegotiation

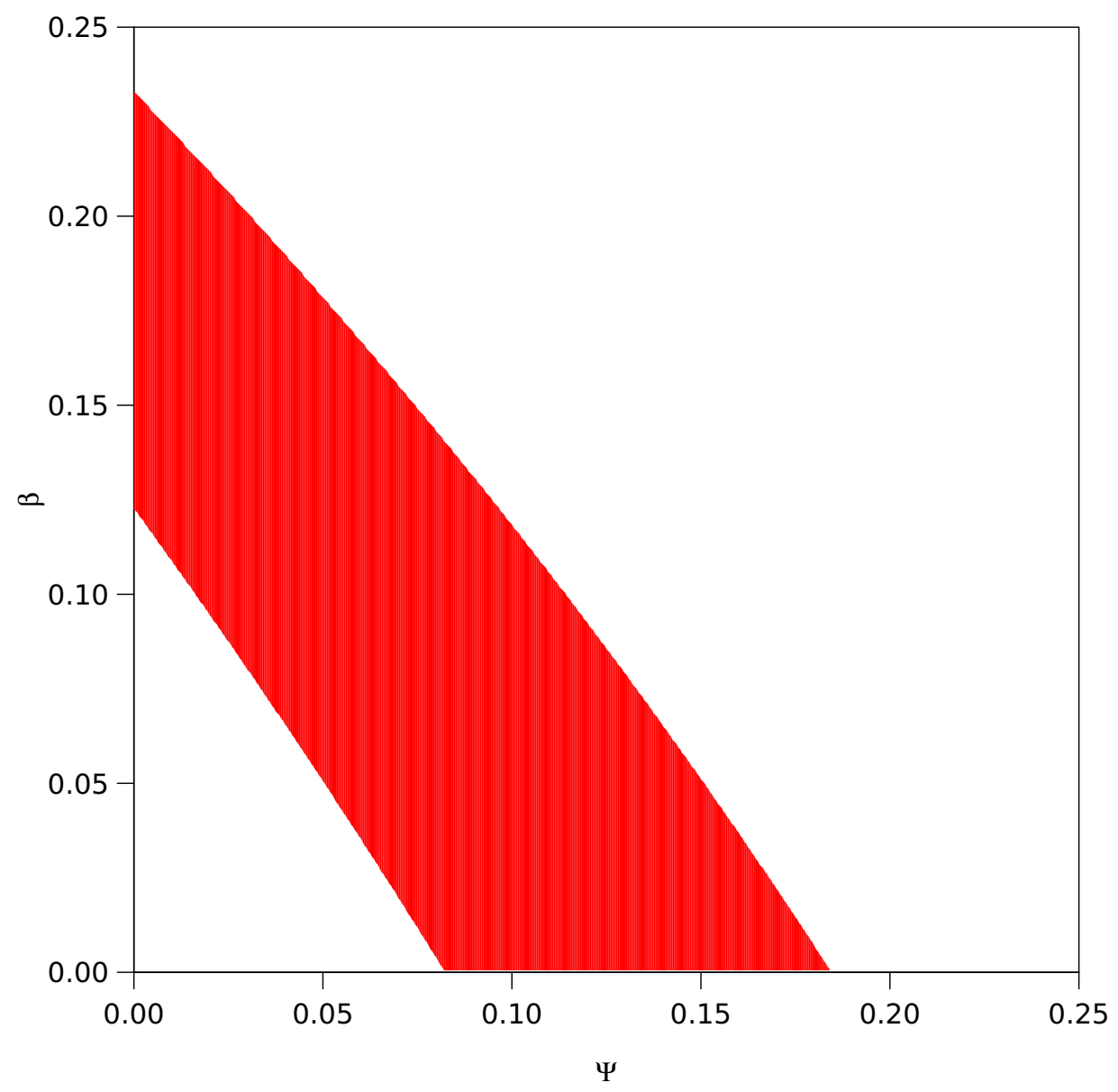

This figure plots the region in which the forced-menu with-Chapter 11 code is better than the laissez-faire code for the contracting parties. As in earlier examples, the base values are $\gamma=1, \bar{L}=0.5, \lambda=0.1, \kappa=0.2$, and $\phi=2$. 